Grant-in-Aid for Scientific Research (S)

Real Estate Markets, Financial Crisis, and Economic Growth

: An Integrated Economic Approach

Working Paper Series No.72

Stock Prices, Regional Housing Prices, and Aggregate Technology Shocks

J iro Yoshida

October, 2017

HIT-REFINED PROJ ECT

Institute of Economic Research, Hitotsubashi University

Naka 2-1, Kunitachi-city, Tokyo 186-8603, J APAN

Tel: +81-42-580-9145

E-mail: hit-refined-sec @ier.hit-u.ac .jp

http://www.ier.hit-u.ac.jp/hit-refined/ 


\title{
Stock Prices, Regional Housing Prices, and Aggregate Technology Shocks
}

\author{
Jiro Yoshida*
}

October 8, 2017

\begin{abstract}
The correlation between stock and housing prices, which is critical for household asset allocations, varies widely by metropolitan area and country. A general equilibrium model demonstrates that an aggregate positive technology shock increases stock prices and housing demand but can decrease housing prices where land supply is elastic because stable future rents are discounted at higher interest rates. Using panel data of U.S. metropolitan areas and OECD countries, I find that the housing price response to TFP shocks as well as the stock-housing correlation are smaller and even negative where the housing supply is elastic. I also find that household equity investment is positively related to housing supply elasticity.
\end{abstract}

JEL Classification: E32, R21, R31, G11

Keywords: macroeconomic shocks, total factor productivity, general equilibrium, regional heterogeneity, house price, housing supply elasticity, asset allocation

*368 Business Building, University Park, PA, 16802, USA. I am particularly grateful to John Quigley, Dwight Jaffee, Richard Stanton, Adam Szeidl, Tom Davidoff, Bob Edelstein, Johan Walden, Nancy Wallace, Francois Ortalo-Magne, Morris Davis, Stijn van Nieuwerburgh, Brent Ambrose, Austin Jaffe, Jan Brueckner, John Campbell, Andrew Lo, Sylvana Tenreyro, Todd Sinai, Harrison Hong, Monika Piazzesi, and Esteban Rossi-Hansberg for their comments and advice. I also thank the seminar participants at the Stockholm School of Economics, University of Tokyo, Hitotsubashi University, National University of Singapore, University of Maastricht, Keio University, Bank of Japan, Kobe University, George Washington University, BIS-HKIMR, and Pennsylvania State University. The financial support of the Japan Society for the Promotion of Science under Grant-in-Aid (Start-up \#20830018 and Scientific Research S\#25220502) and the Institute for Real Estate Studies at the Pennsylvania State University is gratefully acknowledged. All errors are mine. 


\section{Introduction}

Housing is the largest component of household assets. Real estate accounts for $30 \%$ of consumer net wealth based on the U.S. Flow of Funds Accounts and the Survey of Consumer Finances (Poterba and Samwick, 2001) and approximately 60\% of the household portfolio based on the Panel Study of Income Dynamics (Cocco, 2004). In contrast, financial assets account for a much smaller fraction. This is partly because the homeownership rate is high in the United States $(64.5 \%$ in 2014) due to various advantages of homeownership ${ }^{1}$.

Given the high proportion of housing assets in most household portfolios, the correlation between housing and a financial asset plays a critical role in asset allocation. A high correlation suggests a small diversification benefit whereas a low or negative correlation suggests an ability to stabilize wealth and consumption without relying on short selling (Brueckner, 1997; Flavin and Yamashita, 2002, Cocco, 2004, Yao and Zhang, 2005). The correlation structure also influences tenure choice in equilibrium (Ortalo-Magn and Rady, 2002; Sinai and Souleles, 2005; Davidoff, 2006; Li and Yao, 2007).

The actual correlation between stock and housing returns varies significantly by region. Panel A of Figure 1 depicts variations in the stock-housing correlation across 283 U.S. metropolitan areas based on approximately 40 years of quarterly data. The coefficients are approximately 0.2 in Miami and Los Angeles but -0.1 in New Orleans. This implies that stock investment provides greater benefits to homeowners in New Orleans than in Los Angeles and Miami. Although regional variations in house price appreciation are documented by Gyourko, Mayer, and Sinai (2013), the regional variations in correlations between housing and financial assets are less well studied. Panel B depicts similar variations in correlation at the country level for 18 OECD countries. Japan, New Zealand, and Spain have high coefficients (approximately 0.30) but Australia, Germany, Switzerland, Canada, and the United States have negative coefficients ${ }_{2}^{2}$ Thus, stock investment provides a smaller diversification benefit for homeowners in Japan than in the United States.

\footnotetext{
${ }^{1}$ The advantages include tax advantages ( Hendershott and White, 2000), favorable mortgage financing (Poterba, 1984), a hedging motive against rent risk (Sinai and Souleles, 2005), and positive impacts on social and labor market outcomes (Dietz and Haurin, 2003)

2 Cocco (2000) and Flavin and Yamashita (2002) report negative correlations at the national level using PSID. The correlation between the S\&P 500 and the S\&P Case-Shiller Home Price Index between February 1987 and June 2006 is also -0.11. Piazzesi and Schneider (2012) report a negative comovement of housing and equity prices in the United States between 1952 and 2003.
} 
In this study I analyze how geographical variations in stock-housing correlations emerge from an aggregate technology shock and present empirical support. I develop a two-period general equilibrium model that is composed of a goods production sector, a housing production sector, and households. The model demonstrates that the covariation of stock and housing prices is positive where land supply is inelastic but negative for a sufficiently large value of supply elasticity. The data in respect of the U.S. metropolitan areas and OECD countries support this prediction. Furthermore, the cross-country data also show that the equity weight in the household portfolio is positively related to land supply elasticity.

To gain insight into the model, suppose there is a positive permanent technology shock to the general production sector. As a result, both the interest rates and wages increase because the marginal product of capital and labor is larger. These changes have a positive effect on stock prices as long as there are some frictions in capital adjustment. However, the effect on housing prices is ambiguous because of two competing effects. The first effect is that higher wages will increase housing rents through greater housing demand. However, rent increases will be smaller where the housing supply is more elastic. If supply elasticity is infinitely large, there will be no rent increases. The second effect is that a higher interest rate has a negative impact on housing prices because the current housing price is the present discounted value of future rents. Thus, housing prices will increase where the housing supply is inelastic because the first effect is greater than the second. However, housing prices will decrease where the housing supply is sufficiently elastic. As a result, the correlation between stock and housing prices is positive where the housing supply is inelastic but negative where the housing supply is elastic. Thus, aggregate technology shocks can create regional variations in the correlation between stock and housing prices.

For a temporary technology shock, the overall effect is very similar to the case of a permanent shock but the mechanism is slightly more complicated because of the intertemporal substitution of consumption. After a positive temporary shock, households save more to smooth their consumption. Although both interest rates and housing rents increase immediately after the shock, the future interest rate decreases due to a larger amount of saving. At the same time, housing rents decrease because of a lower cost of capital, especially if housing is elastically supplied.

To keep the mechanism simple, I rule out a collateral channel (e.g., Bernanke, Gertler, and Gilchrist, 1999), which would increase the impact of technology shocks but also significantly com- 
plicate the analysis. I also assume that housing supply elasticity is identical under positive and negative technology shocks. Although there is evidence that supply elasticity is smaller under urban decline (Glaesar and Gyourko, 2005), my focus is on fluctuations around a long-run growth path. Thus, I interpret a negative shock as a slower rate of growth rather than urban decline.

In the context of dynamic equilibrium asset pricing, the literature typically ignores housing consumption by implicitly assuming the separability of the utility function. (e.g., Rouwenhorst, 1995: Jermann, 1998). A few studies that introduce housing consumption report that the simulated stock-housing price correlation is almost zero (e.g., Kan, KaiSun, and Leung, 2004; Leung, 2007) 3 This is because these models use a log-linear utility function, which implies a constant expenditure ratio across goods and time. However, the consensus estimate for the price elasticity of housing demand is between -0.5 and -0.8 , indicating consumption complementarity (Mayo, 1981; Ermisch, Findlay, and Gibb, 1996). Thus, I allow for consumption complementarity by using the constant elasticity of substitution form.

I test the predictions of the model by constructing a quarterly panel data set of 283 U.S. metropolitan areas from 1975 to 2014 and 18 OECD countries between 1970 and 2014. The metropolitan area sample represents approximately $73 \%$ of the country on the basis of population. The predictions are that a positive aggregate technology shock will increase (1) interest rates, (2) the aggregate stock price, and (3) housing prices where supply is inelastic, but (4) decrease housing prices where supply is elastic. The model also predicts that (5) the equilibrium correlation between stock and housing is larger where supply is less elastic. Empirical evidence confirms all of these predictions.

Specifically, using the total factor productivity (TFP) growth in the United States as a measure of technology shock, I find that a positive TFP shock increases the U.S. 10-year Treasury rate, the 10-year Treasury Inflation Protected Security (TIPS) rate, the NYSE stock returns, and the CRSP value-weighted stock returns. More importantly, the response of the housing price growth rate to the TFP growth is positive and large in metropolitan areas with inelastic housing supply (e.g., Los Angeles) but negative where the housing supply is elastic (e.g., Atlanta). Similarly, the stock-housing correlation is positive in supply-inelastic metropolitan areas but negative in supply-

\footnotetext{
${ }^{3}$ Most dynamic housing equilibrium models focus on quantity dynamics and do not analyze prices (e.g., Greenwood and Hercowitz, 1991 Benhabib, Rogerson, and Wright, 1991 Davis and Heathcote, 2005).
} 
elastic metropolitan areas. The result is robust to alternative measures of housing supply elasticity: geographical constraints that are measured by the unavailability of land for development and regulatory constraints that are measured by the Wharton Residential Land Use Index. The result also does not depend on the city size. Thus, high stock-housing correlations in large metropolitan areas are not because large local economies are a more significant component of the national economy.

A consistent result is obtained also at the country level. As a measure of land supply elasticity, I use the log per capita land area (i.e., the negative of log population density) because the metropolitan area analysis in this study and other extant studies show that the availability of land critically determines land supply elasticity (e.g., Quigley and Raphael, 2005, Green, Malpezzi, and Mayo, 2005, Saiz, 2010). In the long run, the land supply would be elastic in each country because there are always rural areas to develop. However, the relocation of households and firms to these supply-elastic areas takes a much longer time than the business cycle frequency. Thus, the per capita land area under the current urban structure captures the land supply elasticity in the short and medium run. I construct two variations of the supply elasticity measure: the per capita urban land for cities with more than 500,000 population and the per capita habitable area that includes agricultural land. I find that the TFP growth impacts housing prices positively in countries with inelastic land supply (e.g., Japan, U.K., and Spain) but negatively in countries with elastic land supply (e.g., U.S., Australia, and Canada). Similarly, the correlation between stock returns and the national housing price growth rate is negatively related to land supply elasticity. For example, Japan's per capita habitable area is 0.08 ha and the correlation coefficient is 0.30 whereas Australia's per capita habitable area is 30.25 ha and the correlation coefficient is -0.11 . Furthermore, since large stock-housing correlations imply a smaller diversification benefit of equity investment for homeowners, the household equity holdings are expected to be larger where land supply is elastic. I find that the share of equity holdings in household assets is positively correlated with land supply elasticity (the correlation coefficient is 0.88 ).

The paper is organized as follows. Section II outlines a model that shows how an aggregate technology shock generates regional variation in the stock-housing correlation. Section III reports the empirical results based on the data of U.S. metropolitan areas and OECD countries. Section IV] provides a brief summary and conclusions. 


\section{The Model}

I develop a two-period perfect foresight model of firms and households and derive qualitative predictions to motivate the empirical analysis. There are two goods: a composite good $Y$ and housing services $H$. The former is used either for consumption or augmenting production capital. The latter is a quality-adjusted service flow for consumption; larger service flows are derived either from a larger house or from a higher quality house.

\section{A. Households}

Households are endowed with initial wealth $W_{0}$ and land. They provide capital, land, and labor in each period to earn financial, land, and labor income, respectively, and spend income on the consumption of composite goods, housing services, and savings $W_{1}$. Each household solves the following problem, taking as given housing rents $p_{t}$, land rents $r_{t}$, gross interest rates $i_{t}$, and wages $w_{t}:$

$$
\begin{aligned}
& \max _{\left\{C_{t}, H_{t}\right\}} u\left(C_{1}, H_{1}\right)+\beta u\left(C_{2}, H_{2}\right) \\
& \text { s.t. } C_{1}+p_{1} H_{1}+W_{1}=i_{1} W_{0}+r_{1} T_{1}+w_{1}, \\
& \quad C_{2}+p_{2} H_{2}=i_{2} W_{1}+r_{2} T_{2}+w_{2},
\end{aligned}
$$

where $\beta$ is the subjective discount factor per period, and $u(\bullet)$ is the intra-period utility function over composite goods and housing services. The present specification maintains the durability property of housing consumption because the quantity of housing consumption is determined by the accumulated stock of housing structures. In contrast, households freely choose the consumption of composite goods by changing their savings rate. The intra-period utility function takes the form of constant elasticity of substitution and constant relative risk aversion (CES-CRRA):

$$
u\left(C_{t}, H_{t}\right)=\frac{1}{1-\frac{1}{\theta}}\left(C_{t}^{1-\frac{1}{\rho}}+H_{t}^{1-\frac{1}{\rho}}\right)^{\left(1-\frac{1}{\theta}\right) /\left(1-\frac{1}{\rho}\right)}
$$

where $\rho>0$ is the elasticity of intra-temporal substitution between composite goods and housing services, and $\theta>0$ is the parameter for the elasticity of inter-temporal substitution. The function 
nests special cases of Cobb-Douglas utility when $\rho=1$ and log-linear utility when $\rho=\theta=1$.

Households inelastically supply labor, which is normalized at unity. Regarding land supply, I assume that the marginal cost of providing land for residential use is an increasing function of scale as in Glaeser and Gyourko (2006). The iso-elastic land supply function is $T_{t}=r_{t}^{\mu}$, where $\mu \geq 0$ is the price elasticity of supply. The supply elasticity is determined by such factors as topographic conditions, current population densities, and zoning regulations.

\section{B. Firms}

There are two types of competitive firms. Goods-producing firms produce composite goods by combining business capital $K$ and labor $L$. Each firm solves the following problem in each period $t=\{1,2\}$, taking as given interest rates, wages, and TFP $A_{t}$ :

$$
\max _{K_{t}, L_{t}} Y\left(A_{t}, K_{t}, L_{t}\right)-\left(i_{t}-1+\delta\right) K_{t}-w_{t} L_{t}
$$

where $\delta$ is the depreciation rate of capital $4^{4}$ The production function is Cobb-Douglas, $Y\left(A_{t}, K_{t}, L_{t}\right)=$ $A_{t} K_{t}^{\alpha} L_{t}^{1-\alpha}$, where $\alpha$ is the constant elasticity of output with respect to capital.

Real estate firms produce housing services by combining housing structures $S$ and land $T$. The land should be interpreted as the combination of non-structural local inputs. Each firm solves the following problem in each period, taking as given housing rents, interest rates, land rents, and the TFP $B_{t}: 5$

$$
\max _{S_{t}, T_{t}} p_{t} H\left(B_{t}, S_{t}, T_{t}\right)-\left(i_{t}-1+\delta\right) S_{t}-r_{t} L_{t}
$$

The production function is Cobb-Douglas, $H\left(B_{t}, S_{t}, T_{t}\right)=B_{t} S_{t}^{\gamma} T_{t}^{1-\gamma}$, where $\gamma$ is the constant elasticity of housing services with respect to structure. This production function introduces substitution between land and structure and diminishing marginal products of structure and land, unlike in the linear technology case.

\footnotetext{
${ }^{4}$ For simplicity, I assume a common depreciation rate for capital and the housing structure, but different rates will not alter the qualitative results.

${ }^{5} \mathrm{~A}$ TFP shock to housing production can be interpreted as a preference shock because a higher $B_{t}$ implies that the households are less willing to pay for housing due to their reduced marginal utility. I report the effect of these shocks in Yoshida (2008).
} 


\section{Equilibrium}

The markets are for composite goods, housing services, land, labor, and capital. Walras' law guarantees market clearing in the goods market and the market-clearing conditions are imposed for the other markets.

Definition 1: A competitive equilibrium in this 2-period economy with perfect foresight is the allocation $\left\{C_{t}, H_{t}, W_{1}, Y_{t}, K_{t}, L_{t}, S_{t}, T_{t},\right\}$ and the prices $\left\{p_{t}, w_{t}, i_{t}, r_{t},\right\}$ for $t=\{1,2\}$ such that 1. optimality is achieved for households, goods-producing firms, and real estate firms, and 2. all market-clearing conditions and resource constraints are met.

The optimality conditions of goods-producing firms are:

$$
\begin{gathered}
K_{t}: i_{t}-1+\delta=\alpha A_{t}\left(L_{t} / K_{t}\right)^{1-\alpha}, \\
L_{t}: w_{t}=(1-\alpha) A_{t}\left(K_{t} / L_{t}\right)^{\alpha} .
\end{gathered}
$$

Similarly, the optimality conditions of real estate firms are:

$$
\begin{aligned}
& S_{t}: i_{t}-1+\delta=p_{t} \gamma B_{t}\left(T_{t} / S_{t}\right)^{1-\gamma} \\
& T_{t}: r_{t}=p_{t}(1-\gamma) B_{t}\left(S_{t} / T_{t}\right)^{\gamma} .
\end{aligned}
$$

As usual, the interest rate is equal to $1-\delta$ plus the marginal product of capital (MPK), which is also equal to $1-\delta$ plus the marginal product of the housing structure (MPHS) in units of the numeraire. In equilibrium, capital allocations are adjusted until the marginal product of capital is equated across sectors. The wage is equal to the marginal product of labor, and the land rent is equal to the marginal housing product of land, in units of the numeraire. 
The optimality conditions of households are:

$$
\begin{aligned}
p_{t}^{\rho} H_{t} & =C_{t}, \text { and } \\
\frac{1}{i_{2}} & =\beta\left[\frac{C_{2}}{C_{1}}\left(\frac{1+\left(H_{2} / C_{2}\right)^{1-1 / \rho}}{1+\left(H_{1} / C_{1}\right)^{1-1 / \rho}}\right)^{\frac{\theta-\rho}{(1-\rho)}}\right]^{-\frac{1}{\theta}} \\
& =\beta\left[\frac{C_{2}}{C_{1}}\left(\frac{\left(1+p_{2}^{1-\rho}\right)^{\frac{1}{1-\rho}}}{\left(1+p_{1}^{1-\rho}\right)^{\frac{1}{1-\rho}}}\right)^{\theta-\rho}\right]^{-\frac{1}{\theta}} .
\end{aligned}
$$

The reciprocal of the interest rate equals the inter-temporal marginal rate of substitution (IMRS), which is the discount factor in this economy. The Euler equation 12 shows that the IMRS depends not only on the consumption growth but also on growth of the consumption ratio $H_{t} / C_{t}$, or, equivalently, the growth of housing rents $p_{t}$. The consumption of composite goods, housing, and housing rents are determined in general equilibrium and their changes cannot be identified merely with reference to the Euler equation. Indeed, I show that the relationship between the consumption growth and the discount factor changes signs depending on the parameter values and the type of shock involved 6

The multi-sector structure necessitates a numerical solution. The detailed derivation of the equilibrium is shown in Appendix A.

\section{Analysis of Equilibrium}

The focus is on the effect of a permanent and temporary TFP shock to the composite goods production sector. A temporary shock is defined as $\Delta A_{1}>0$ and $\Delta A_{2}=0$, and a permanent shock is defined as $\Delta A_{1}=\Delta A_{2}>0$. I use a $10 \%$ increase in the TFP as a shock. I report comparative statics with respect to the land supply elasticity $(\mu)$, the elasticity of intra-temporal substitution between $C$ and $H(\rho)$, and the parameter for inter-temporal substitution $(\theta)$. The values of other parameters are: $\alpha=1 / 3, \beta=0.9$, and $\delta=0.5$. Yoshida (2008) reports a more complete set of analyses including the effect of the anticipated future productivity growth and housing productivity

\footnotetext{
${ }^{6}$ The analyses provide a fresh look at several related results: Tesar (1993), who considers an endowment shock to the non-tradables; and Piazzesi, Schneider, and Tuzel (2007), who empirically investigate the relationship between the discount factor and the expenditure share of housing.
} 
shocks.

\section{D.1. Interest Rate}

Table I presents a percentage-point change in interest rates due to an increase in TFP in the composite goods production. An interest rate change is calculated for alternative sets of parameter values for land supply elasticity $(\mu)$, the inter-temporal elasticity of substitution $(\theta)$, and the intratemporal elasticity of substitution $(\rho)$. Panels A and B exhibit the positive effects of a permanent shock on both the first- and second-period interest rates for all parameter values. With a positive shock to goods production, the marginal product of capital increases although more capital is employed in the goods production. The land supply elasticity has only a small impact but the elasticities of consumption substitution have larger impacts. The effect on the interest rate is greater when the elasticities of substitution are small. This is because the current demand for both composite goods and housing becomes less elastic as the elasticity of substitution becomes smaller. Panels $\mathrm{C}$ and D present the effect of a temporary shock. The first-period interest rate increases but the second-period interest rate decreases. This is because households save more in the first period to smooth consumption, and the capital supply increases in the second period.

\section{D.2. Housing Rent}

Table II presents the effect on housing rents. Housing rents increase after a positive technology shock because higher productivity makes the composite goods cheap relative to housing rents. The effect is qualitatively similar to the effect on interest rates; that is, an impact is larger when the elasticity of substitution is smaller, and a temporary shock will decrease the second period rent. This is because the marginal product of the housing structure is equilibrated with the marginal product of capital. However, an important difference is that the land supply elasticity has a large impact on the magnitude of the rent increase. The rent increase is greater if the land supply elasticity is smaller (columns 1-3) because a shift in the housing demand results in a greater change in the rent. 


\section{D.3. Housing Price}

The housing price is defined as the present discounted value of housing rents for a unit amount of housing assets:

$$
P_{0}=\frac{p_{1}}{i_{1}}+\frac{p_{2}}{i_{1} i_{2}}
$$

The above analysis demonstrates that both housing rents and interest rates change in the same direction after a technology shock. For example, after a positive permanent shock, both the numerator and the denominator will increase in both terms in Eq. 113 . Thus, the overall effect on housing prices depends on the relative magnitude of these changes. An increase in housing rents is

large where the land supply is inelastic, but an increase in interest rates does not depend much on land supply elasticity. Thus, a positive technology shock is more likely to increase housing prices where the land supply is inelastic but can decrease housing prices where the land supply is elastic. The effect is slightly more complicated for a temporary shock; both the numerator and the denominator will increase in the first term, but the numerator and a component of the denominator $\left(i_{2}\right)$ will decrease in the second term. Thus, a temporary positive shock is more likely to be associated with a decrease in housing prices.

Panels A and B of Table III present the change in housing prices caused by a positive technology shock. With a permanent shock, housing prices increase where the land supply is inelastic (columns 1-3) but decrease where the land supply is elastic (columns 4-6). This relationship holds for all combinations of parameter values for elasticities of substitution although the magnitude of an effect is larger if the elasticity of intra-termporal substitution is smaller. A small elasticity of intratemporal substitution indicates housing demand is inelastic because housing services are more complementary to composite goods. As predicted, with a temporary shock, housing prices decrease regardless of the land supply elasticity.

Panel (a) of Figure 2 depicts the change in housing prices induced by a positive permanent shock for different values of land supply elasticity. Three lines represent alternative combinations of parameter values for the elasticities of substitution. All lines slope downward, indicating that the land supply elasticity has a negative effect on the housing price appreciation. The price response is positive where the land supply is inelastic, but as the land supply elasticity increases, the price response is reduced and even reversed. The housing appreciation rate is negative if the supply 
elasticity is 1 or larger. The slope of a graph is steepest when the elasticity of intra-temporal substitution is small.

\section{D.4. Stock Price}

The stock price is equivalent to the value of the installed business capital when firms are fully equity-financed. Although the price of business capital is always one in the current frictionless model, it is easy to predict the price of capital in the presence of adjustment costs. The price of capital will always change in the same direction as the equilibrium quantity of capital at the time of a shock (e.g., Geanakoplos, Magill, and Quinzii, 2002; Abel, 2003). Rouwenhorst (1995) also demonstrates the equivalence of the share price and the amount of capital in his business cycle model. For example, the price of capital will increase and remain higher than unity while the business capital is gradually adjusted toward a higher level in the new equilibrium. Thus, I take a short-cut approach to use the change in equilibrium capital as a proxy for change in the stock price instead of introducing slow capital adjustments within each period.

Panels C and D of Table III present the change in the proxy for the stock price. Not surprisingly, the stock price generally increases with a positive shock to goods production regardless of whether a shock is temporary or permanent. The effect is larger when elasticities of substitution are greater because more capital is allocated to goods production after a positive productivity shock. However, land supply elasticity does not have a large impact.

\section{D.5. Covariation of Stock and Housing Prices}

The covariation of asset prices in response to a technology shock is measured by the product of the percentage change in the two prices. This measure is determined by both the sign and magnitude of a price change. Panel (b) of Figure 2 depicts the covariation between stock and housing prices for different values of land supply elasticity and substitution elasticities. The covariation is decreasing in the land supply elasticity. This is because a housing price response depends more on the land supply elasticity than a stock price response. The covariation is positive where the land supply is inelastic but negative where it is elastic. This result implies a perfectly positive correlation where the land supply is inelastic and a perfectly negative correlation where it is elastic. However, this covariation is generated by a single technology shock to the goods production sector. In a real 
economy, the correlation coefficients will be less than perfect because there are multiple sources of economic fluctuations. Thus, the model predicts that the empirical correlation coefficients will exhibit a similar pattern to that shown in this graph.

\section{Empirical Analysis}

The theoretical model predicts that a positive aggregate technology shock will (1) increase housing prices where the supply is inelastic but (2) decrease housing prices where the supply is elastic. A positive shock will also (3) increase the interest rates and (4) the aggregate stock price. The model also predicts that (5) the equilibrium correlation between stock and housing is larger where the supply is less elastic. I test these predictions by using data for U.S. metropolitan areas and OECD countries.

\section{A. U.S. Metropolitan Area Analysis}

\section{A.1. Data}

I construct a quarterly unbalanced panel of 283 metropolitan areas (CBSAs) between 1975, Q3 and 2014, Q2. The housing price index (HPI) data are obtained from the Federal Housing Finance Agency (FHFA). The FHFA all-transaction HPI is a weighted, repeat-sales index, which measures average price changes in repeat sales or refinancings of the same properties contained in the mortgage sample of Fannie Mae or Freddie Mac since January 1975.

The HPI data set is merged with the housing supply elasticity data set constructed by Saiz (2010). The sample is reduced to 283 CBSAs, which represents $72.8 \%$ of the national population. By this supply elasticity measure, Miami, Los Angeles, San Francisco, and New York exhibit relatively inelastic housing supply. In contrast, Wichita, New Orleans, and Atlanta exhibit relatively elastic housing supply. I also use two alternative measures of housing supply inelasticity. The first is the share of area unavailable for development within a 50-km radius, which represents geographical constraints (Saiz, 2010). The second alternative measure is the Wharton Residential Land Use Regulation Index (WRLURI) produced by Gyourko, Saiz, and Summers (2008). This measure captures the intensity of local growth control policies in multiple dimensions. Lower values in the WRLURI are associated with more laissez-faire policies toward real estate development and 
higher values are associated with zoning regulations or project approval practices that constrain new residential real estate development.

The national aggregate stock price index is the value-weighted composite index of all common stock listed on the New York Stock Exchange; this is published by the OECD and was retrieved from the Federal Reserve Bank of St. Louis. For a robustness check, I also use the CRSP valueweighted index with dividends. This index includes dividend returns and covers the AMEX and Nasdaq exchanges in addition to the NYSE.

The TFP measure is the utilization-adjusted quarterly TFP series for the U.S. business sector estimated by Fernald (2014) 7 This measure of technology shocks is more sophisticated than the Solow residual and is estimated at a higher frequency than other measures such as the annual BLS multifactor productivity measure.

Table [V presents the descriptive statistics for the entire sample and for three subsamples of high, medium, and low supply elasticity. The mean quarterly housing price growth rate is $0.89 \%$ and is monotonically decreasing in supply elasticity. The population is also monotonically decreasing in supply elasticity. In the empirical analysis, this negative relationship between the supply elasticity and the population is controlled for. The mean quarterly stock return is $1.95 \%$, and the mean quarterly TFP growth rate is $0.23 \%$. The mean value of the housing supply elasticity is 2.387 . The Wharton Regulation Index and the Share Unavailable for Development are obviously negatively related to supply elasticity.

\section{A.2. $\quad$ TFP and Housing Prices}

To test the first and second predictions, I estimate the following equation.

$$
d \ln H P I_{i t}=\alpha+\beta d \ln T F P_{t}+\gamma \ln S U P_{i}+\delta\left(d \ln T F P_{t} \times S U P_{i}\right)+Y E A R_{s}+\varepsilon_{i t},
$$

where $d \ln H P I_{i t}$ denotes the continuously-compounded quarterly housing price growth rate for metropolitan area $i$ in quarter $t, d \ln T F P_{t}$ denotes the continuously-compounded quarterly TFP growth rate, $\ln S U P_{i}$ denotes the logarithm of the housing supply elasticity, and $\varepsilon_{i t}$ denotes an error term. Standard errors are adjusted for heteroskedasticity and clustering at the metropolitan

\footnotetext{
${ }^{7}$ The most recent data set is updated on February 06, 2015, 5:08 PM.
} 
area level to account for the time-series correlation in the error term for each metropolitan area. I also estimate the equation by controlling for year fixed effects 8 I also estimate the above equations by using 2-quarter lagged TFP growth because there may be a lag in the response of the housing prices to a technology shock.

Table $\mathrm{V}$ reports the estimated coefficients for Eq. 14. In column 1, the coefficient on the TFP growth is 0.330 , which represents the effect of a $1 \%$ growth in TFP on the housing prices in a metropolitan area where log supply elasticity is zero (i.e., supply elasticity is one). Since the mean log supply elasticity is 0.72 and the mean elasticity is 2.39 , this coefficient corresponds to a metropolitan area with less elastic supply than the average.

The estimated coefficient on the interaction term between the TFP growth and the log supply elasticity is -0.262 and is statistically significant at the $1 \%$ level. Thus, the sensitivity of housing prices to the TFP growth is decreasing in supply elasticity. The response of the housing prices can be negative where the housing supply is sufficiently elastic. A one standard deviation increase in the TFP growth $(0.68 \%$ per quarter or $2.76 \%$ per year) will increase the housing prices by $1.28 \%$ per year in a metropolitan area with the smallest log elasticity of -0.52 but will decrease housing prices by $0.89 \%$ per year in a metropolitan area with the largest log elasticity of 2.50 .

Other coefficients are also consistent with this expectation. A coefficient of 0.011 on the constant term corresponds to the base housing price growth rate of $4.5 \%$ per year without any technological progress in the unit supply elasticity. The housing price growth rate is higher in a less supply-elastic metropolitan area. On the basis of the coefficient on the log supply elasticity $(-0.003)$, the mean annual housing price growth rate without any technological progress is $5.15 \%$ in the least supplyelastic metropolitan area and $1.41 \%$ in the most supply-elastic metropolitan area. This finding is consistent with the result of Gyourko, Mayer, and Sinai (2013).

The result does not change significantly when the year fixed effects are included (column 2). In particular, the effect on the interaction term between the TFP growth and the supply elasticity is -0.317 and is statistically significant at the $1 \%$ level. However, the estimated coefficient on the TFP growth is smaller (0.243). This is not surprising because this estimate is based only on a within-year variation in housing prices. Part of the technological effect is created by medium-term

\footnotetext{
${ }^{8}$ Since $d \ln T F P_{t}$ is a quarterly aggregate variable, quarter fixed effects cannot be included. Similarly, since $S U P_{i}$ is a metropolitan area-specific variable, metropolitan area fixed effects cannot be included.
} 
(across-years) technological progress.

There is a concern that the size of a metropolitan area is a confounding factor that creates a bias in the estimated effect of the supply elasticity on the housing price sensitivity. The descriptive statistics reported in Table IV] reveal a negative correlation between the housing supply elasticity and the city population. The significant effect of the supply elasticity may be obtained because the economies of large metropolitan areas represent the national economy better than that of small metropolitan areas. To account for potentially nonlinear effects, I interact all regressors with metropolitan area-size tertile dummies and estimate coefficients for each metropolitan area size $j$ :

$$
d \operatorname{lnHPI_{it}}=\mu_{j} \times\left[\alpha+\beta d \operatorname{lnTFP} P_{t}+\gamma \ln S U P_{i}+\delta\left(d \operatorname{lnTFP} P_{t} \times S U P_{i}\right)\right]+Y E A R_{s}+\varepsilon_{i t} .
$$

Column 3 reports the estimation result. The coefficient on the interaction term between the TFP growth and the supply elasticity is -0.245 for the large metropolitan areas. This coefficient is not statistically different by city size. The effect of the supply elasticity on the housing price sensitivity is even stronger in the medium-sized metropolitan areas than in the large metropolitan areas. Thus, the effect of the supply elasticity on the housing price sensitivity is not confounded by city size. Other coefficients are also consistent with the previous estimations. Columns 4 through 6 report the result when 2-quarter lagged TFP growth is used as a regressor. The results are consistent with those with a contemporaneous value of TFP growth.

Figure 3 visualizes the negative relationship between the log supply elasticity and the housing price sensitivity to technology shocks for three categories of city size 9 The log supply elasticity is on the horizontal axis. The metropolitan areas with small elasticity, such as Miami, Los Angeles, and San Francisco, have relatively large coefficients whereas the metropolitan areas with large elasticity, such as Indianapolis, Kansas City, Austin, and Atlanta, have relatively small coefficients. The metropolitan areas are categorized into three groups on the basis of their population. Although the large metropolitan areas tend to have smaller supply elasticity than the small metropolitan areas, each group exhibits significant variations in the supply elasticity. All three regression lines slope downward, indicating that the housing price sensitivity is small where the supply elasticity is large irrespective of city size.

\footnotetext{
${ }^{9}$ The figure plots the metropolitan area-specific regression coefficient $\beta+\gamma_{i}$ from a regression: $d \ln H P I_{i t}=$ $\alpha+\beta d \ln T F P_{t}+\gamma_{i} d \ln T F P_{t} \times M S A_{i}+\delta_{i} M S A_{i}+\varepsilon_{i t}$, where $M S A_{i}$ denotes metropolitan area dummies.
} 


\section{A.3. TFP, Stock Price, and Interest Rates}

The theoretical model also predicts that a positive technology shock will increase interest rates and stock prices. In particular, the effect on interest rates is the source of a negative response of housing prices to a positive technology shock. To test these predictions, I estimate the effect of the TFP growth on the stock returns, the 10-year Treasury rates, the consumer price index (CPI), and the 10-year TIPS rates. Because the estimated TFP growth may lead or lag the financial market-based indicators, I use a 1-quarter forwarded value and a 1-quarter lagged value in addition to the contemporaneous value of the TFP growth.

Columns 1-3 in Table VI present the estimation result for the stock returns. The contemporaneous value of the TFP growth has a positive effect (2.734) at the $5 \%$ level. A one standard deviation increase in the annual TFP growth will increase the stock return by $7.48 \%$. A one-quarter lead in the TFP growth also exhibits a positive effect at the $10 \%$ significance level. Thus, stock returns tend to slightly lead the TFP growth. Indeed, the CRSP returns lead the TFP growth by one quarter. Columns 4-6 present the result for quarterly changes in the 10-year Treasury rate. The contemporaneous value of the TFP growth has a positive effect $(0.256)$ at the $1 \%$ level. A one standard deviation increase in the annual TFP growth will increase the 10-year Treasury rate by 70 basis points. To gain an insight into the effect on real interest rates, I present the results for the quarterly CPI growth rate in columns 7-9. None of the estimated coefficients is statistically significant although the TFP growth may have a long-lasting impact on the CPI with significant lags. Columns 10-12 present the results for the quarterly change in the 10-year TIPS rate. Although there are only 47 observations, the 1-quarter lagged value of the TFP growth has a positive effect (0.067) at the $10 \%$ level. A one standard deviation increase in the annual TFP growth will increase the 10-year TIPS rate by 18 basis points. Thus, I find positive effects of technology shocks on stock returns and interest rates.

\section{A.4. Stock and Housing Prices}

Now I test the equilibrium correlation between the aggregate stock prices and the regional housing prices. The estimation equations are analogous to Eqs. 14 and 15 with $d \ln T F P_{t}$ being replaced by $d \ln S P_{t}$, which denotes the continuously-compounded quarterly stock return. 
Columns 1-3 of Table VII present the estimation results when the contemporaneous value of stock returns is used. Columns 1 and 2 correspond to Eq. (14) without and with the year fixed effects, respectively, and column 3 corresponds to Eq. (15), which includes the metropolitan areasize dummies. The estimated coefficients are consistent with each other in all three specifications. In particular, the coefficient on the interaction term between stock returns and the supply elasticity is negative and statistically significant at the $1 \%$ level. Also, these coefficients are not significantly different between the metropolitan area size groups. On the basis of the result in column 1, a one standard deviation increase in the annual stock return (29.8\% per year) is associated with a $1.26 \%$ increase in the housing prices in the least supply-elastic metropolitan area but with a $0.72 \%$ decrease in the most supply-elastic metropolitan area.

Columns 4-6 present the result when 2-quarter lagged stock returns are used. The estimation result is largely unchanged except that the coefficient on the stock return is larger. On the basis of the result in column 4, a one standard deviation increase in the 2-quarter ahead stock return is associated with a $2.24 \%$ increase in the housing prices in the least supply-elastic metropolitan area but with a $0.73 \%$ decrease in the most supply-elastic metropolitan area.

Figure 4 depicts the negative relationship between the supply elasticity and the correlation between the stock and housing returns ${ }^{10}$ This figure is similar to Figure 3 , supply-inelastic metropolitan areas such as Miami, Los Angeles, and San Francisco tend to have higher correlations between housing and stock returns than supply-elastic metropolitan areas such as Indianapolis, Kansas City, and Atlanta. The regression lines almost identically slope downward for all three size groups.

As a robustness check, I also estimate the same equations by using the CRSP value-weighted index with dividends. Since the CRSP return leads the TFP growth by one quarter, I use 1- and 3-quarter lagged values of CRSP returns. Table VIII presents the estimation result. The result is consistent with that based on the NYSE composite index. The coefficient on the interaction term between the stock returns and the supply elasticity is negative and statistically significant at the $1 \%$ level in all specifications.

\footnotetext{
${ }^{10}$ The figure plots the metropolitan area-specific regression coefficient $\beta+\gamma_{i}$ from a regression: $d \ln H P I_{i t}=$ $\alpha+\beta d \ln S P_{t}+\gamma_{i} d \ln S P_{t} \times M S A_{i}+\delta_{i} M S A_{i}+\varepsilon_{i t}$.
} 


\section{A.5. Alternative Measures of Supply Inelasticity}

There may be a concern that the estimated supply elasticity is subject to an endogeneity problem. To address this concern, I use two alternative measures of supply inelasticity: the share of area unavailable for development within a 50-km radius, which is estimated by Saiz (2010), and the WRLURI produced by Gyourko, Saiz, and Summers (2008). The first measure captures the geographical constraints and the second measure captures the regulatory constraints. Both measures are exogenous to price fluctuations in the short to medium term. The regression equation is identical to Eq. (14) except that the log supply elasticity is replaced by these inelasticity measures.

In Table IX, columns 1 and 2 present the estimation result with the share unavailable for development, and columns 3 and 4 present the result with the WRLURI. For both measures of inelasticity, the coefficients are positive and significant at the $1 \%$ level on the supply inelasticity measure, the interaction term between the TFP growth and the inelasticity measure, and the interaction between the stock returns and the inelasticity measure. These results are consistent with the result based on the estimated supply elasticity; that is, the housing price sensitivity is stronger in the less supply-elastic metropolitan areas. Figure 5 visualizes this result by plotting the metropolitan area-specific coefficients on the TFP growth (upper panels) and the coefficients on the stock returns (lower panels). For both measures, a positive relationship is apparent between the estimated coefficients and the supply inelasticity (the share unavailable for development is on the left panels and the WRLURI is on the right panels).

\section{B. Cross-Country Analysis}

\section{B.1. Data}

I construct two unbalanced panel data sets of 18 OECD countries. The first is an annual panel that includes the TFP growth rate between 1971 and 2011, and the second is a quarterly panel that includes the stock returns between 1970, Q1 and 2014, Q4 ${ }^{11}$ National housing price indexes are obtained from the Long-Term Series of Nominal Residential Property Prices published by the Bank for International Settlements 12 The TFP data are obtained from the Penn World Table

\footnotetext{
${ }^{11}$ The sample period is shorter for several countries because of shorter stock return series: Denmark (1983, Q1), Belgium and Spain (1985, Q1), and Norway (1986, Q1).

${ }^{12}$ The data description is obtained at http://www.bis.org/statistics/pp_long_documentation.pdf.
} 
8.0 ${ }^{13}$ The stock price data are obtained from the OECD Main Economic Indicators through the Federal Reserve Bank of St. Louis.

The land supply elasticity is not readily available for all countries. Thus, I construct two measures of land supply elasticity at the national level. The key insight is that geographical constraints and the population density are the major determinants of the housing supply elasticity Quigley and Raphael, 2005; Green, Malpezzi, and Mayo, 2005, Saiz, 2010). In particular, the reciprocal of the population density is positively related to the land supply elasticity. The first measure I construct is the logarithm of the per capita urban land. The data are obtained from the 2015 Demographia World Urban Areas, which provides an inventory of the population and corresponding land area for urban areas with a population of more than 500,000 ${ }^{14}$ I divide the total urban land area by the total urban population for each country to construct the per capita urban land. Because the distribution of this variable is positively skewed I take a logarithm for regression analysis. The second measure is the logarithm of the per capita habitable area. The national population data are obtained from the OECD. The habitable area is calculated as the land area minus the inland water and the forest and woodland in FAOSTAT. The habitable area includes agricultural land, which could be converted to residential land in some countries. Although I use both elasticity measures, the per capita urban land would be more consistent with the use of national housing price indexes because these price indexes mostly reflect urban housing prices.

Panel A of Table $\mathrm{X}$ presents the descriptive statistics of the quarterly panel. The mean quarterly housing price growth rate is $1.53 \%$, and the mean quarterly stock return is $1.73 \%$. The volatility of the housing price index is $1.35 \%$ on average but it significantly varies by country because each country uses a unique method of data collection and index construction. Since the focus of this study is the correlations of housing prices with the TFP and the stock prices, in the empirical analysis I normalize the housing price growth rate, the stock return, and the TFP growth rate so that the volatility of each variable becomes unity in each country. By this normalization, the regression coefficients in the following empirical analysis can be interpreted as correlation coefficients 15 The average population is 50 million, of which 24 million are urban residents in cities with a population of more than 500,000. The average national land area is 177 million ha, of which approximately

\footnotetext{
${ }^{13}$ See Inklaar and Timmer $(2013)$ for the data construction method.

${ }^{14}$ The data are available at http://www.demographia.com/db-worldua.pdf.

${ }^{15}$ The regression coefficient, $\left(X^{\prime} X\right)^{-1} X^{\prime} Y$, equals the correlation coefficient when $X$ and $Y$ have unit variance.
} 
$63 \%$ is habitable and $8 \%$ is urban land. The average per capita habitable area is 3.7 ha, and the average per capita urban land is 0.04 ha $\left(400 \mathrm{~m}^{2}\right)$. Panel B presents the statistics of the annual panel. Due to a few countries having different sample periods, the descriptive statistics are slightly different to those in the quarterly panel. A unique variable in the annual panel is the TFP growth rate, which ranges from $-8.1 \%$ to $5.4 \%$ with a mean value of $0.28 \%$.

\section{B.2. TFP and Housing Prices}

I estimate the following equation:

$$
d \ln S H P I_{i t}=\alpha+\beta d \ln S T F P_{i, t-1}+\gamma \ln S U P_{i}+\delta\left(d \ln S T F P_{i, t-1} \times S U P_{i}\right)+Y E A R_{t}+\varepsilon_{i t},
$$

where $d \ln S H P I_{i t}$ is the standardized annual housing price growth rate (with unit variance) and $d \ln S T F P_{i, t-1}$ is the 1-year lagged standardized annual TFP growth rate. I take a 1-year lag because it exhibits the strongest relationship between the housing price and the TFP growth rate. This is probably because, in some countries, housing markets are less efficient and housing data are collected in a less timely manner than in the United States. The regression coefficient is interpreted as a correlation coefficient as I explain in III.B.1.

Table XI presents the estimation result. Column 1 shows that the average correlation is 0.215 without conditioning on the land supply elasticity. Thus, on average, technology shocks have positive effects on housing prices. Columns 2 through 5 present the result when the land supply elasticity is included. The coefficient on the interaction term between the TFP growth and the land supply elasticity is negative in all specifications and statistically significant in three of them. For a one standard-deviation increase in the land supply elasticity measure, the correlation coefficient decreases by 0.055 on the basis of column 2 and 0.060 on the basis of column 4 . The result is similar when the year fixed effects are included. Thus, the effect of technology shocks is smaller where land supply is more elastic.

Figure 6 visualizes the negative relationship between the correlation coefficient and the land supply elasticity by plotting the country-specific correlation coefficient against a land supply elasticity measure ${ }^{16}$ On the basis of the per capita urban land (Panel (a)), the most supply elastic

\footnotetext{
${ }^{16}$ Specifically, I report $\beta+\gamma_{i}$ from a regression: $d \ln S H P I_{i t}=\alpha+\beta d \ln S T F P_{i, t-1}+\gamma_{i} d \ln S T F P_{i, t-1} \times C O U N T R Y_{i}+$
} 
countries (U.S. and Australia) have coefficients around 0.1, and the least supply elastic countries (Spain, U.K., and Japan) have coefficients between 0.3 and 0.5. On the basis of the per capita habitable area (Panel (b)), the most supply elastic countries (Australia and Canada) have coefficients between 0 and 0.1 , and the least supply elastic countries (Japan and the Netherlands) have coefficients between 0.3 and 0.4 .

\section{B.3. Stock and Housing Prices}

The correlation between stock and housing prices is also negatively related to the land supply elasticity. Table XII presents the estimation result of Eq. (16) with $d \ln S T F P_{i t}$ being replaced by the standardized stock return $\left(d \ln S S P_{i t}\right)$. Data are quarterly. For the same reason that the TFP growth is lagged by 1 year, I use 4- and 5-quarter lagged stock returns. Consistent with the result for the U.S. metropolitan areas, on average, the stock returns are positively correlated with the housing price growth rates. For example, the correlation is 0.78 when evaluated at the mean log per capita urban land in column 1. Furthermore, the estimated coefficient on the interaction term between the stock returns and the supply elasticity is negative in all specifications and statistically significant at least at the $5 \%$ level when log per capita urban land is used (columns 1-4). A one standarddeviation increase in the land supply elasticity measure decreases the correlation coefficient by 0.054 on the basis of column 1 and 0.044 on the basis of column 5. Thus, the correlation coefficients are smaller in countries where the land supply is more elastic.

Figure 7 visualizes the negative relationship between the stock-housing correlation and the land supply elasticity ${ }^{17}$ On the basis of per capita urban land (Panel (a)), the most supply elastic countries (U.S. and Australia) have negative coefficients around -0.1, and the least supply elastic countries (Spain, U.K., and Japan) have positive coefficients around 0.15. On the basis of the per capita habitable area (Panel (b)), the most supply elastic countries (Australia and Canada) also have coefficients around -0.1 , and the least supply elastic countries (Japan and the Netherlands) have coefficients around 1.5. In both panels, a negative relationship is apparent.

$\delta_{i} C O U N T R Y_{i}+\varepsilon_{i t}$, where COUNTRY $Y_{i}$ denotes country dummies.

${ }^{17}$ I report $\beta+\gamma_{i}$ from a regression: $d \ln S H P I_{i t}=\alpha+\beta d \ln S S P_{i t}+\gamma_{i} d \ln S S P_{i t} \times C O U N T R Y_{i}+\delta_{i} C O U N T R Y_{i}+\varepsilon_{i t}$. 


\section{B.4. Equity Holdings}

The regional variation in the correlation between the stock and housing prices has important implications for the household equity holdings. In particular, in countries where tax and other advantages are provided to homeowners, housing is often a dominant asset in the household portfolio. In this case, the equity investment decision is made given the current holding of housing assets. If stock and housing prices are positively correlated, a small weight should be assigned to equity in the optimal portfolio (Flavin and Yamashita, 2002; Cocco, 2004). Thus, the model in the present study predicts that households in a land-inelastic economy will put smaller weights on stocks. In contrast, in a land-elastic economy, households should be more willing to hold stocks in their portfolio because equity investment serves as a hedge against housing price risk.

Figure 8 depicts the share of equity holdings in households' total assets at the end of 2001 plotted against the land supply elasticity measures for seven OECD countries (Canada, France, Germany, Italy, Japan, the U.K., and the U.S.). The equity share data are obtained from Bank of Japan (2003), which makes various adjustments on flow of funds accounts so that the seven countries become comparable (e.g., an adjustment as to whether to include the equity share of private businesses in households' assets). The figure shows a clear positive relationship between the equity holdings and the land supply elasticity. In Panel (a), the correlation coefficient is 0.88 , and the t-statistic of the slope coefficient is 4.2318 There are large variations in the equity shares: U.S. (0.34), France (0.29), Canada (0.28), Italy (0.22), Germany (0.14), U.K. (0.13), and Japan (0.07). As for the economic significance, an increase in the log per capita urban land by one is associated with an $18 \%$ higher share of equity holdings. For example, a U.S. urban resident has a 3.9 and 3.5 times larger urban area than a resident in the United Kingdom and Japan, respectively. At the same time, a household in the United States holds a 21 and 27 percentage point larger share of equity than a household in the United Kingdom and Japan, respectively. Although seven countries are not enough to make a decisive conclusion, the available data support the model's predictions. The link between households' portfolio choice and the land supply elasticity is a new finding of this study.

\footnotetext{
${ }^{18}$ The result is robust when mutual funds are added to equity holdings; the correlation coefficient is 0.49. However, including mutual funds is not desirable since mutual funds contain fixed income and global investments.
} 


\section{Conclusions}

In this paper, I provide evidence that housing prices are more positively correlated with technology shocks and stock prices where the housing supply is less elastic. Moreover, I report that the correlations are negative where the supply elasticity is sufficiently large. These relationships are observed at the level of both the U.S. metropolitan areas and the OECD countries. A general equilibrium model reveals how this regional variation in the correlations, especially a negative correlation in the supply elastic regions, emerges from an aggregate shock to the goods production sector. A positive technology shock will increase housing rents but only by a small amount where the housing supply is elastic. At the same time, the positive shock will increase the interest rates in the economy, and thus housing prices decrease where the supply is elastic. I also provide evidence that household equity investments are positively correlated with the housing supply elasticity because equity investments provide greater diversification benefits where the housing supply is elastic. 


\section{References}

Abel, Andrew B., 2003, The effects of a baby boom on stock prices and capital accumulation in the presence of social security, Econometrica 71, 551-578.

Bank of Japan, 2003, Shikin junkan tokei no kokusai hikaku (international comparison of flow of funds accounts), Discussion paper Research and Statistics Department, Bank of Japan.

Benhabib, Jess, Richard Rogerson, and Randall Wright, 1991, Homework in macroeconomics: Household production and aggregate fluctuations, Journal of Political Economy 99, 1166-1187.

Bernanke, Ben S., Mark Gertler, and Simon Gilchrist, 1999, Asset prices, consumption, and the business cycle, , vol. 1 of Handbook of Macroeconomics . chap. 21, pp. 1341-1393 (Elsevier).

Brueckner, Jan K., 1997, Consumption and investment motives and the portfolio choices of homeowners, Journal of Real Estate Finance and Economics 15, 159-180.

Cocco, Joao F., 2000, Hedging house price risk with incomplete markets, Working paper AFA 2001 New Orleans Meetings.

— 2004, Portfolio choice in the presence of housing, Review of Financial Studies 18, 535-567.

Davidoff, Thomas, 2006, Labor income, housing prices, and homeownership, Journal of Urban Economics 59, 209-235.

Davis, Morris A., and Jonathan Heathcote, 2005, Housing and the business cycle, International Economic Review 46, 751-784.

Dietz, Robert D., and Donald R. Haurin, 2003, The social and private micro-level consequences of homeownership, Journal of Urban Economics 54, 401 - 450.

Ermisch, J. F., J. Findlay, and K. Gibb, 1996, The price elasticity of housing demand in britain: Issues of sample selection, Journal of Housing Economics 5, 64-86.

Fernald, John, 2014, A quarterly, utilization-adjusted series on total factor productivity, Discussion paper. 
Flavin, Marjorie, and Takashi Yamashita, 2002, Owner-occupied housing and the composition of the household portfolio, American Economic Review 92, 345-362.

Geanakoplos, John, Michael Magill, and Martine Quinzii, 2002, Demography and the long-run predictability of the stock market, Cowles Foundation Discussion Papers 1380 Cowles Foundation, Yale University.

Glaesar, Edward, and Joseph Gyourko, 2005, Urban decline and durable housing, Journal of Political Economy 113, 345-375.

Glaeser, Edward L., and Joseph Gyourko, 2006, Housing dynamics, NBER Working Papers 12787 National Bureau of Economic Research, Inc.

Green, Richard K., Stephen Malpezzi, and Stephen K. Mayo, 2005, Metropolitan-specific estimates of the price elasticity of supply of housing and their sources, American Economic Review 95, $334-339$.

Greenwood, Jeremy, and Zvi Hercowitz, 1991, The allocation of capital and time over the business cycle, Journal of Political Economy 99, 1188-214.

Gyourko, Joseph, Christopher Mayer, and Todd Sinai, 2013, Superstar cities, American Economic Journal: Economic Policy 5, 167-99.

Gyourko, Joseph, Albert Saiz, and Anita Summers, 2008, A new measure of the local regulatory environment for housing markets: The wharton residential land use regulatory index, Urban Studies 45, 693-729.

Hendershott, Patric H., and Michael White, 2000, Taxing and Subsidizing Housing Investment: The Rise and Fall of Housing's Favored Status, NBER Working Papers 7928 National Bureau of Economic Research, Inc.

Inklaar, Robert, and Marcel P. Timmer, 2013, Capital, Labor and TFP in PWT8.0, mimeo Groningen Growth and Development Centre, University of Groningen.

Jermann, Urban J., 1998, Asset pricing in production economies, Journal of Monetary Economics $41,257-275$. 
Kan, Kamhon, Kwong Sunny KaiSun, and Charles KaYui Leung, 2004, The dynamics and volatility of commercial and residential property prices: Theory and evidence, Journal of Regional Science $44,95-123$.

Leung, Charles K.Y., 2007, Equilibrium correlations of asset price and return, Journal of Real Estate Finance and Economics 34, 233-256.

Li, Wenli, and Rui Yao, 2007, The life-cycle effects of house price changes, Journal of Money, Credit and Banking 39, 1375-1409.

Mayo, Stephen K., 1981, Theory and estimation in the economics of housing demand, Journal of Urban Economics 10, 95-116.

Ortalo-Magn, Franois, and Sven Rady, 2002, Tenure choice and the riskiness of non-housing consumption, Journal of Housing Economics 11, 266 - 279.

Piazzesi, Monika, and Martin Schneider, 2012, Inflation and the Price of Real Assets, Working paper Stanford University.

— and Selale Tuzel, 2007, Housing, consumption and asset pricing, Journal of Financial Economics 83, 531-569.

Poterba, James M., 1984, Tax subsidies to owner-occupied housing: An asset-market approach, The Quarterly Journal of Economics 99, pp. 729-752.

— , and Andrew Samwick, 2001, Household Portfolio Allocation over the Life Cycle, in Aging Issues in the United States and JapanNBER Chapters . pp. 65-104 (National Bureau of Economic Research, Inc).

Quigley, John M., and Steven Raphael, 2005, Regulation and the high cost of housing in california, American Economic Review 95, 323-328.

Rouwenhorst, K. Geert, 1995, Asset pricing implications of equilibrium business cycle models, in Thomas F. Cooley, ed.: Frontiers of Business Cycle Research (Princeton University Press: Princeton New Jersey). 
Saiz, Albert, 2010, The geographic determinants of housing supply, The Quarterly Journal of Economics 125, 1253-1296.

Sinai, Todd, and Nicholas S. Souleles, 2005, Owner-occupied housing as a hedge against rent risk, The Quarterly Journal of Economics 120, pp. 763-789.

Tesar, Linda L., 1993, International risk-sharing and non-traded goods, Journal of International Economics 35, 69-89.

Yao, Rui, and Harold H. Zhang, 2005, Optimal consumption and portfolio choices with risky housing and borrowing constraints, Review of Financial Studies 18, 197-239.

Yoshida, Jiro, 2008, Technology Shocks and Asset Price Dynamics:The Role of Housing in General Equilibrium, CARF F-Series CARF-F-119 Center for Advanced Research in Finance, Faculty of Economics, The University of Tokyo. 


\begin{tabular}{|c|c|c|c|c|c|c|c|}
\hline \multicolumn{8}{|c|}{ Panel A: Permanent Shock, First Period Interest Rate } \\
\hline \multirow{5}{*}{$\rho$} & \multirow{5}{*}{$\begin{array}{l}0.6 \\
1.0 \\
1.4\end{array}$} & \multicolumn{3}{|c|}{0} & \multicolumn{3}{|c|}{5} \\
\hline & & 0.6 & 1.0 & 1.4 & 0.6 & 1.0 & 1.4 \\
\hline & & 6.36 & 5.89 & 5.54 & 6.58 & 5.97 & 5.49 \\
\hline & & 5.69 & 5.32 & 5.04 & 5.73 & 5.32 & 4.99 \\
\hline & & 5.16 & 4.88 & 4.65 & 5.08 & 4.80 & 4.55 \\
\hline \multicolumn{8}{|c|}{ Panel B: Permanent Shock, Second Period Interest Rate } \\
\hline \multirow{5}{*}{$\rho$} & \multirow{5}{*}{$\begin{array}{l}0.6 \\
1.0 \\
1.4\end{array}$} & \multicolumn{3}{|c|}{0} & \multicolumn{3}{|c|}{5} \\
\hline & & 0.6 & 1.0 & 1.4 & 0.6 & 1.0 & 1.4 \\
\hline & & 9.08 & 7.99 & 7.23 & 8.64 & 7.24 & 6.25 \\
\hline & & 6.22 & 5.37 & 4.77 & 6.32 & 5.37 & 4.66 \\
\hline & & 4.90 & 4.17 & 3.65 & 5.16 & 4.43 & 3.87 \\
\hline \multicolumn{8}{|c|}{ Panel C: Temporary Shock, First Period Interest Rate } \\
\hline \multirow{5}{*}{$\rho$} & \multirow{5}{*}{$\begin{array}{l}0.6 \\
1.0 \\
1.4\end{array}$} & \multicolumn{3}{|c|}{0} & \multicolumn{3}{|c|}{5} \\
\hline & & 0.6 & 1.0 & 1.4 & 0.6 & 1.0 & 1.4 \\
\hline & & 6.01 & 5.72 & 5.50 & 6.11 & 5.78 & 5.51 \\
\hline & & 5.31 & 5.10 & 4.94 & 5.29 & 5.10 & 4.94 \\
\hline & & 4.78 & 4.63 & 4.52 & 4.69 & 4.57 & 4.46 \\
\hline \multicolumn{8}{|c|}{ Panel D: Temporary Shock, Second Period Interest Rate } \\
\hline \multirow{5}{*}{$\rho$} & \multirow{2}{*}{$\begin{array}{l}\mu \\
\theta\end{array}$} & \multicolumn{3}{|c|}{0} & \multicolumn{3}{|c|}{5} \\
\hline & & 0.6 & 1.0 & 1.4 & 0.6 & 1.0 & 1.4 \\
\hline & 0.6 & -4.87 & -5.16 & -5.36 & -5.48 & -5.61 & -5.70 \\
\hline & 1.0 & -3.78 & -3.98 & -4.12 & -3.87 & -3.98 & -4.06 \\
\hline & 1.4 & -3.21 & -3.35 & -3.46 & -3.06 & -3.14 & -3.21 \\
\hline
\end{tabular}

Table I: The Effect on Interest Rates

This table presents the changes in the first- and second-period interest rates by a temporary shock (Panels A and B) or permanent shock (Panels C and D). A change is expressed in percentage points. A shock is a $10 \%$ increase in the TFP for the composite goods production. The parameter values are: $\mu \in\{0,5\}$ for the land supply elasticity, $\theta \in\{0.6,1.0,1.4\}$ for the inter-temporal elasticity of substitution, and $\rho \in\{0.6,1.0,1.4\}$ for the intra-temporal elasticity of substitution. 


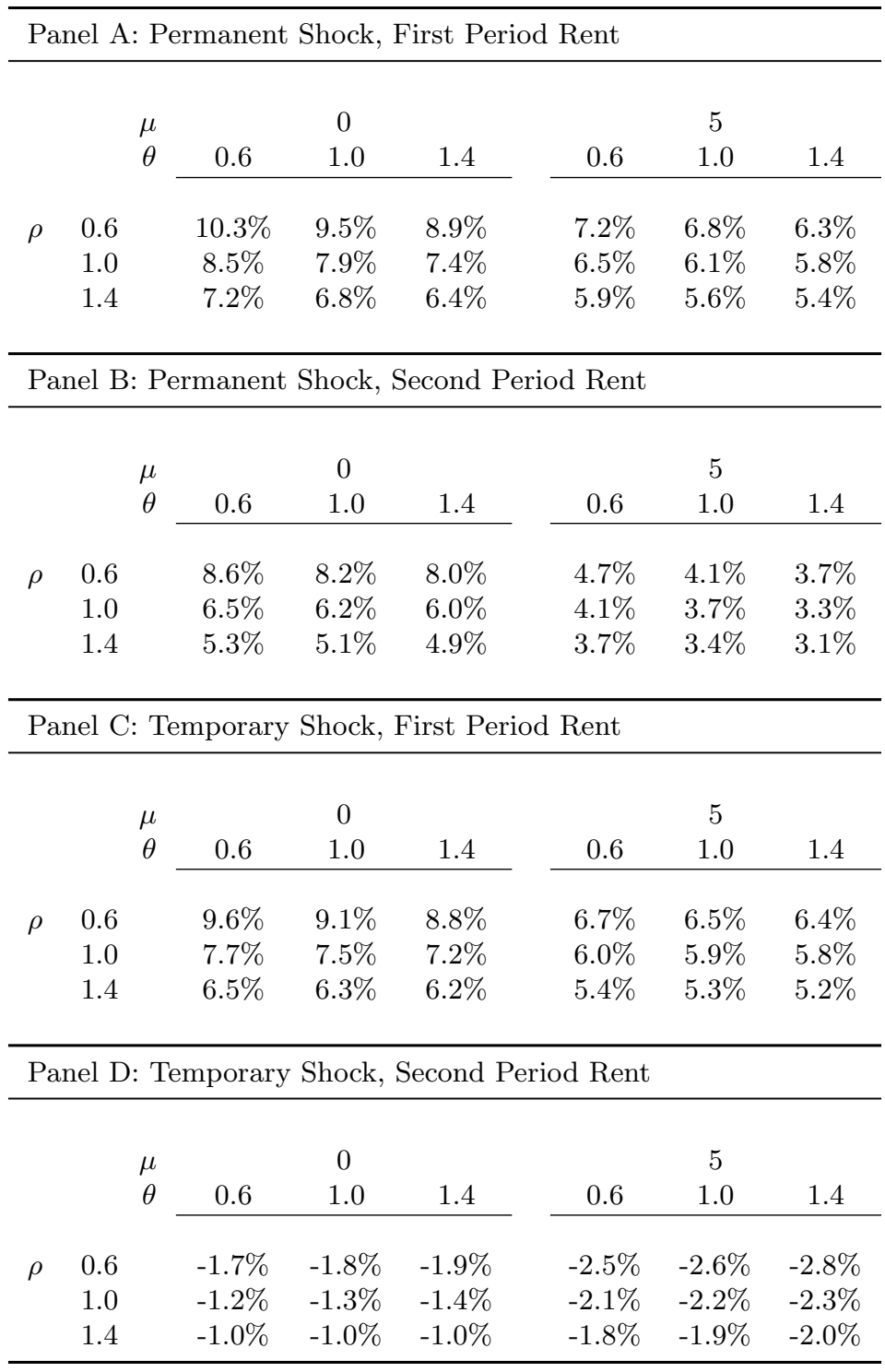

Table II: The Effect on Housing Rents

This table presents the changes in the first- and second-period housing rents by a temporary shock (Panels A and B) or permanent shock (Panels C and D). A shock is a $10 \%$ increase in the TFP for the composite goods production. The parameter values are: $\mu \in\{0,5\}$ for the land supply elasticity, $\theta \in\{0.6,1.0,1.4\}$ for the inter-temporal elasticity of substitution, and $\rho \in\{0.6,1.0,1.4\}$ for the intra-temporal elasticity of substitution. 


\begin{tabular}{|c|c|c|c|c|c|c|c|}
\hline \multicolumn{8}{|c|}{ Panel A: Housing Price, Permanent Shock } \\
\hline \multirow{5}{*}{$\rho$} & \multirow{2}{*}{$\begin{array}{l}\mu \\
\theta\end{array}$} & \multicolumn{3}{|c|}{0} & \multicolumn{3}{|c|}{5} \\
\hline & & 0.6 & 1.0 & 1.4 & 0.6 & 1.0 & 1.4 \\
\hline & 0.6 & $1.0 \%$ & $1.1 \%$ & $1.1 \%$ & $-1.6 \%$ & $-1.4 \%$ & $-1.3 \%$ \\
\hline & 1.0 & $0.6 \%$ & $0.7 \%$ & $0.7 \%$ & $-1.3 \%$ & $-1.2 \%$ & $-1.1 \%$ \\
\hline & 1.4 & $0.3 \%$ & $0.4 \%$ & $0.4 \%$ & $-1.2 \%$ & $-1.1 \%$ & $-1.0 \%$ \\
\hline
\end{tabular}

\begin{tabular}{|c|c|c|c|c|c|c|c|}
\hline \multicolumn{8}{|c|}{ Panel B: Housing Price, Temporary Shock } \\
\hline \multirow{5}{*}{$\rho$} & \multirow{2}{*}{$\begin{array}{c}\mu \\
\theta\end{array}$} & \multicolumn{3}{|c|}{0} & \multicolumn{3}{|c|}{5} \\
\hline & & 0.6 & 1.0 & 1.4 & 0.6 & 1.0 & 1.4 \\
\hline & 0.6 & $-0.3 \%$ & $-0.3 \%$ & $-0.3 \%$ & $-1.5 \%$ & $-1.4 \%$ & $-1.4 \%$ \\
\hline & 1.0 & $-0.3 \%$ & $-0.3 \%$ & $-0.3 \%$ & $-1.3 \%$ & $-1.3 \%$ & $-1.3 \%$ \\
\hline & 1.4 & $-0.3 \%$ & $-0.3 \%$ & $-0.3 \%$ & $-1.2 \%$ & $-1.2 \%$ & $-1.2 \%$ \\
\hline
\end{tabular}

Panel C: Stock Price, Permanent Shock

\begin{tabular}{|c|c|c|c|c|c|c|c|}
\hline & & & 0 & & & 5 & \\
\hline & 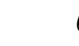 & 0.6 & 1.0 & 1.4 & 0.6 & 1.0 & 1.4 \\
\hline$\rho$ & 0.6 & $-0.3 \%$ & $0.5 \%$ & $1.2 \%$ & $0.3 \%$ & $1.2 \%$ & $1.9 \%$ \\
\hline & 1.0 & $1.7 \%$ & $2.3 \%$ & $2.8 \%$ & $1.7 \%$ & $2.3 \%$ & $2.8 \%$ \\
\hline & 1.4 & $3.1 \%$ & $3.6 \%$ & $4.0 \%$ & $2.8 \%$ & $3.2 \%$ & $3.7 \%$ \\
\hline
\end{tabular}

Panel D: Stock Price, Temporary Shock

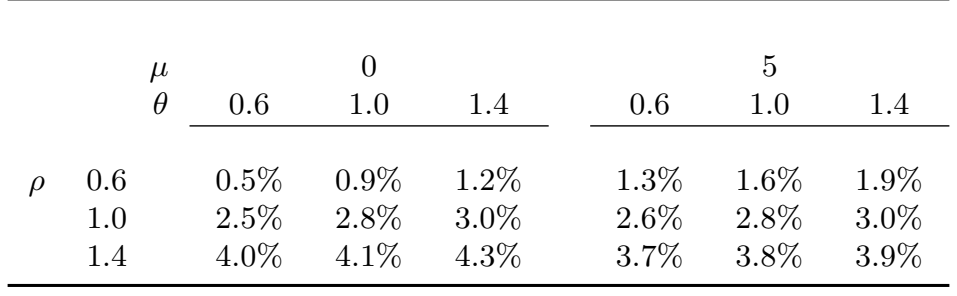

Table III: The Effect on Asset Prices

This table presents the changes in the housing prices (Panels A and B) and stock prices (Panels C and D). A shock is a 10\% increase in the TFP for the composite goods production. The parameter values are: $\mu \in\{0,5\}$ for the land supply elasticity, $\theta \in\{0.6,1.0,1.4\}$ for the inter-temporal elasticity of substitution, and $\rho \in\{0.6,1.0,1.4\}$ for the intra-temporal elasticity of substitution. 


\begin{tabular}{|c|c|c|c|c|c|c|c|c|}
\hline \multirow[b]{2}{*}{ VARIABLES } & \multicolumn{2}{|c|}{$\begin{array}{l}\text { Entire Sample } \\
283 \text { CBSAs } \\
\text { N: } 36,717\end{array}$} & \multicolumn{2}{|c|}{$\begin{array}{c}\text { Low Elasticity } \\
(<1.68) \\
95 \text { CBSAs } \\
\text { N: } 13,339\end{array}$} & \multicolumn{2}{|c|}{$\begin{array}{c}\text { Medium Elasticity } \\
(>1.68,<2.75) \\
94 \text { CBSAs } \\
\text { N: } 12,052\end{array}$} & \multicolumn{2}{|c|}{$\begin{array}{c}\text { High Elasticity } \\
(>2.75) \\
94 \text { CBSAs } \\
\text { N: } 11,326\end{array}$} \\
\hline & Mean & S.D. & Mean & S.D. & Mean & S.D. & Mean & S.D. \\
\hline Quarterly log home price change & 0.0089 & 0.0255 & 0.0110 & 0.0279 & 0.0082 & 0.0251 & 0.0072 & 0.0227 \\
\hline Quarterly stock return & 0.0195 & 0.0652 & 0.0198 & 0.0646 & 0.0197 & 0.0653 & 0.0190 & 0.0656 \\
\hline Quarterly log TFP change & 0.0023 & 0.0068 & 0.0022 & 0.0069 & 0.0023 & 0.0067 & 0.0023 & 0.0066 \\
\hline Population in 2000 Census $(1,000 \mathrm{~s})$ & 1,107 & 1,692 & 2,097 & 2,355 & 668 & 811 & 407 & 442 \\
\hline Housing supply elasticity & 2.387 & 1.364 & 1.187 & 0.316 & 2.221 & 0.304 & 3.975 & 1.255 \\
\hline Log housing supply elasticity & 0.722 & 0.549 & 0.133 & 0.283 & 0.789 & 0.139 & 1.344 & 0.253 \\
\hline Wharton Regulation Index & -0.034 & 0.825 & 0.495 & 0.801 & 0.052 & 0.649 & -0.750 & 0.393 \\
\hline Share unavailable for development & 0.261 & 0.212 & 0.455 & 0.191 & 0.204 & 0.132 & 0.093 & 0.090 \\
\hline
\end{tabular}

Table IV: Descriptive Statistics of Quarterly MSA Panel (Unbalanced, 1975, Q3-2014, Q2) 


\begin{tabular}{|c|c|c|c|c|c|c|}
\hline $\begin{array}{l}\text { DEPENDENT VARIABLE: } \\
\text { Quarterly HPI Growth Rate }\end{array}$ & (1) & $(2)$ & $(3)$ & (4) & $(5)$ & (6) \\
\hline TFP Growth & $\begin{array}{l}0.330^{* * *} \\
(0.031)\end{array}$ & $\begin{array}{l}0.243^{* * *} \\
(0.031)\end{array}$ & $\begin{array}{l}0.219^{* * *} \\
(0.034)\end{array}$ & $\begin{array}{l}0.453^{* * *} \\
(0.038)\end{array}$ & $\begin{array}{l}0.312^{* * *} \\
(0.044)\end{array}$ & $\begin{array}{l}0.298^{* * *} \\
(0.051)\end{array}$ \\
\hline × D(Medium MSAs $)$ & & & $\begin{array}{l}0.142 \\
(0.087)\end{array}$ & & & $\begin{array}{l}0.100 \\
(0.097)\end{array}$ \\
\hline$\times \mathrm{D}($ Small MSAs $)$ & & & $\begin{array}{l}-0.177 \\
(0.110)\end{array}$ & & & $\begin{array}{l}-0.179 \\
(0.116)\end{array}$ \\
\hline Supply Elasticity & $\begin{array}{l}-0.003^{* * *} \\
(0.000)\end{array}$ & $\begin{array}{l}-0.002^{* * *} \\
(0.000)\end{array}$ & $\begin{array}{l}-0.002^{* * *} \\
(0.000)\end{array}$ & $\begin{array}{l}-0.003^{* * *} \\
(0.000)\end{array}$ & $\begin{array}{l}-0.002^{* * *} \\
(0.000)\end{array}$ & $\begin{array}{l}-0.002^{* * *} \\
(0.000)\end{array}$ \\
\hline$\times \mathrm{D}($ Medium MSAs $)$ & & & $\begin{array}{l}-0.000 \\
(0.001)\end{array}$ & & & $\begin{array}{l}-0.000 \\
(0.001)\end{array}$ \\
\hline$\times \mathrm{D}($ Small MSAs $)$ & & & $\begin{array}{l}0.001^{* *} \\
(0.001)\end{array}$ & & & $\begin{array}{l}0.001^{* *} \\
(0.001)\end{array}$ \\
\hline TFP Growth $\times$ Supply Elasticity & $\begin{array}{l}-0.262^{* * *} \\
(0.034)\end{array}$ & $\begin{array}{l}-0.317^{* * *} \\
(0.035)\end{array}$ & $\begin{array}{l}-0.245^{* * *} \\
(0.056)\end{array}$ & $\begin{array}{l}-0.266^{* * *} \\
(0.039)\end{array}$ & $\begin{array}{l}-0.314^{* * *} \\
(0.040)\end{array}$ & $\begin{array}{l}-0.272^{* * * *} \\
(0.068)\end{array}$ \\
\hline × D(Medium MSAs $)$ & & & $\begin{array}{l}-0.178 \\
(0.112)\end{array}$ & & & $\begin{array}{l}-0.100 \\
(0.118)\end{array}$ \\
\hline$\times \mathrm{D}($ Small MSAs $)$ & & & $\begin{array}{l}0.050 \\
(0.097)\end{array}$ & & & $\begin{array}{l}0.075 \\
(0.100)\end{array}$ \\
\hline Constant & $\begin{array}{l}0.011^{* * *} \\
(0.000)\end{array}$ & $\begin{array}{l}0.010^{* * *} \\
(0.000)\end{array}$ & $\begin{array}{l}0.010^{* * *} \\
(0.000)\end{array}$ & $\begin{array}{l}0.010^{* * *} \\
(0.000)\end{array}$ & $\begin{array}{l}0.010^{* * *} \\
(0.000)\end{array}$ & $\begin{array}{l}0.010^{* * *} \\
(0.000)\end{array}$ \\
\hline D(Medium MSAs) & & & $\begin{array}{l}-0.000 \\
(0.001)\end{array}$ & & & $\begin{array}{l}0.000 \\
(0.001)\end{array}$ \\
\hline $\mathrm{D}$ (Small MSAs) & & & $\begin{array}{l}0.000 \\
(0.001)\end{array}$ & & & $\begin{array}{l}0.000 \\
(0.001)\end{array}$ \\
\hline Number of Lags in TFP Growth & 0 & 0 & 0 & 2 quarters & 2 quarters & 2 quarters \\
\hline Year f.e. & No & Yes & Yes & No & Yes & Yes \\
\hline Observations & 36,717 & 36,717 & 36,717 & 36,717 & 36,717 & 36,717 \\
\hline $\mathrm{F}$ & 81.23 & 62.35 & 25.86 & 98.04 & 50.53 & 23.84 \\
\hline Adjusted R-squared & 0.00789 & 0.139 & 0.140 & 0.0115 & 0.139 & 0.140 \\
\hline
\end{tabular}

Table V: Home Price Growth and TFP Growth

This table presents the results from the regressions of the quarterly home price growth rate (FHFA all-transaction HPI) on the total factor productivity growth (estimated by Fernald, 2014 and updated on February 06, 2015), the log housing supply elasticity (estimated by Saiz 2010), and their interaction terms. The data are an unbalanced quarterly panel of 283 metropolitan areas from 1975, Q3 to 2014, Q2. The TFP growth rates are contemporaneous (columns 1-3) and 2-quarter lagged (columns 4-6). In columns 3 and 6 , the coefficients are estimated for each population tertile of the metropolitan areas by using dummy variables for the medium-sized and small metropolitan areas. The year fixed effects are included in columns $2,3,5$, and 6 . The standard errors adjusted for heteroskedasticity and clustering at the metropolitan area level are reported in parentheses. The statistical significance is denoted by ${ }^{* * *},{ }^{* *}$, and $*$ at the $1 \%, 5 \%$, and $10 \%$ level, respectively. 


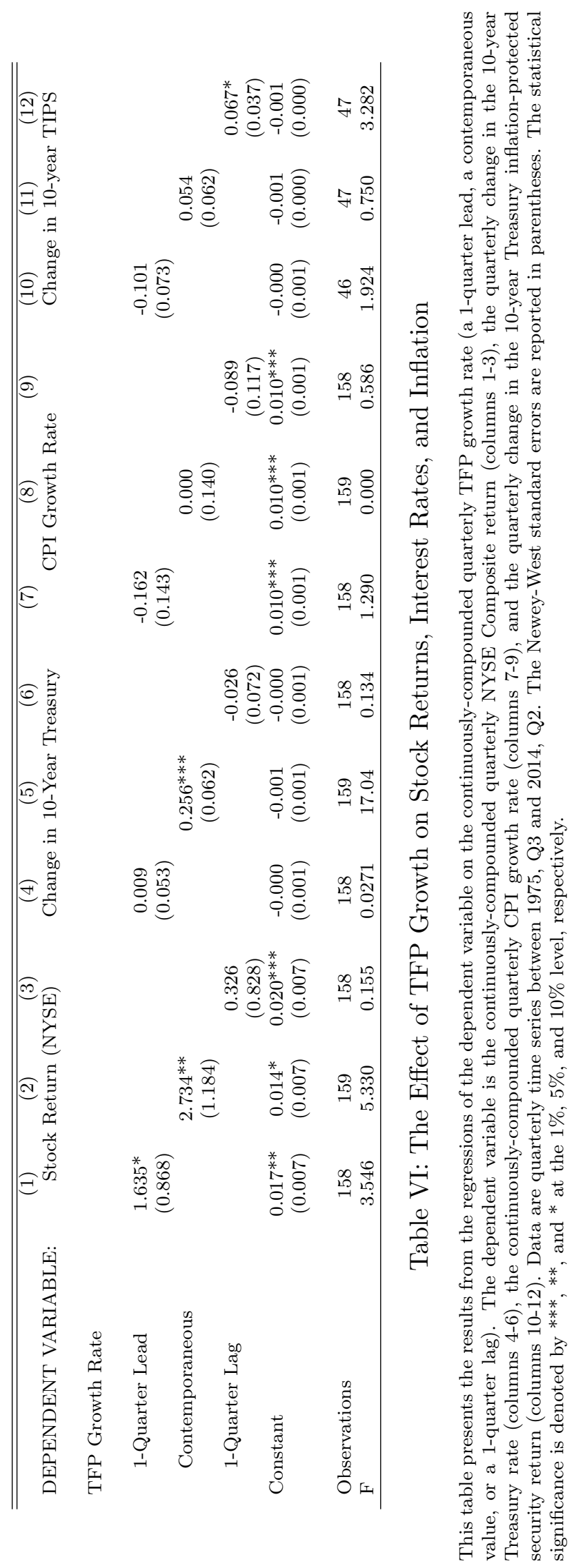




\begin{tabular}{|c|c|c|c|c|c|c|}
\hline $\begin{array}{l}\text { DEPENDENT VARIABLE: } \\
\text { Quarterly HPI Growth Rate }\end{array}$ & $(1)$ & $(2)$ & $(3)$ & (4) & $(5)$ & $(6)$ \\
\hline Stock Return (NYSE Composite) & $\begin{array}{l}0.031^{* * *} \\
(0.003)\end{array}$ & $\begin{array}{l}0.000 \\
(0.003)\end{array}$ & $\begin{array}{l}0.003 \\
(0.004)\end{array}$ & $\begin{array}{l}0.058^{* * *} \\
(0.003)\end{array}$ & $\begin{array}{l}0.049^{* * *} \\
(0.003)\end{array}$ & $\begin{array}{l}0.051^{* * *} \\
(0.004)\end{array}$ \\
\hline$\times \mathrm{D}($ Medium MSAs $)$ & & & $\begin{array}{l}-0.006 \\
(0.007)\end{array}$ & & & $\begin{array}{l}0.002 \\
(0.008)\end{array}$ \\
\hline$\times \mathrm{D}($ Small MSAs $)$ & & & $\begin{array}{l}-0.013 \\
(0.009)\end{array}$ & & & $\begin{array}{l}-0.017^{* *} \\
(0.008)\end{array}$ \\
\hline Supply Elasticity & $\begin{array}{l}-0.003^{* * *} \\
(0.000)\end{array}$ & $\begin{array}{l}-0.002^{* * *} \\
(0.000)\end{array}$ & $\begin{array}{l}-0.002^{* * *} \\
(0.000)\end{array}$ & $\begin{array}{l}-0.003^{* * *} \\
(0.000)\end{array}$ & $\begin{array}{l}-0.002^{* * *} \\
(0.000)\end{array}$ & $\begin{array}{l}-0.002^{* * *} \\
(0.000)\end{array}$ \\
\hline$\times \mathrm{D}($ Medium MSAs $)$ & & & $\begin{array}{l}-0.001 \\
(0.001)\end{array}$ & & & $\begin{array}{l}-0.000 \\
(0.001)\end{array}$ \\
\hline$\times \mathrm{D}($ Small MSAs $)$ & & & $\begin{array}{l}0.001^{*} \\
(0.001)\end{array}$ & & & $\begin{array}{l}0.001^{*} \\
(0.001)\end{array}$ \\
\hline Stock Return $\times$ Supply Elasticity & $\begin{array}{l}-0.022^{* * *} \\
(0.003)\end{array}$ & $\begin{array}{l}-0.026^{* * *} \\
(0.003)\end{array}$ & $\begin{array}{l}-0.028^{* * *} \\
(0.005)\end{array}$ & $\begin{array}{l}-0.033^{* * *} \\
(0.003)\end{array}$ & $\begin{array}{l}-0.037^{* * *} \\
(0.003)\end{array}$ & $\begin{array}{l}-0.037^{* * *} \\
(0.005)\end{array}$ \\
\hline$\times \mathrm{D}($ Medium MSAs $)$ & & & $\begin{array}{l}0.009 \\
(0.009)\end{array}$ & & & $\begin{array}{l}-0.005 \\
(0.009)\end{array}$ \\
\hline$\times \mathrm{D}($ Small MSAs $)$ & & & $\begin{array}{l}0.009 \\
(0.008)\end{array}$ & & & $\begin{array}{l}0.013^{*} \\
(0.008)\end{array}$ \\
\hline Constant & $\begin{array}{l}0.011^{* * *} \\
(0.000)\end{array}$ & $\begin{array}{l}0.011^{* * *} \\
(0.000)\end{array}$ & $\begin{array}{l}0.011^{* * *} \\
(0.000)\end{array}$ & $\begin{array}{l}0.010^{* * *} \\
(0.000)\end{array}$ & $\begin{array}{l}0.010^{* * *} \\
(0.000)\end{array}$ & $\begin{array}{l}0.010^{* * *} \\
(0.000)\end{array}$ \\
\hline D(Medium MSAs) & & & $\begin{array}{l}0.000 \\
(0.001)\end{array}$ & & & $\begin{array}{l}0.000 \\
(0.001)\end{array}$ \\
\hline D(Small MSAs) & & & $\begin{array}{l}0.000 \\
(0.001)\end{array}$ & & & $\begin{array}{l}0.000 \\
(0.000)\end{array}$ \\
\hline Number of Lags in TFP Growth & 0 & 0 & 0 & 2 quarters & 2 quarters & 2 quarters \\
\hline Year f.e. & No & Yes & Yes & No & Yes & Yes \\
\hline Observations & 36,717 & 36,717 & 36,717 & 36,717 & 36,717 & 36,717 \\
\hline $\mathrm{F}$ & 86.16 & 70.36 & 29.55 & 172.5 & 94.69 & 35.25 \\
\hline Adjusted R-squared & 0.00728 & 0.140 & 0.140 & 0.0148 & 0.142 & 0.142 \\
\hline
\end{tabular}

Table VII: Home Price Growth and Stock Returns

This table presents the results from the regressions of the quarterly home price growth rate (FHFA all-transaction HPI) on the aggregate stock returns (NYSE composite index), the log housing supply elasticity (estimated by Saiz, 2010), and their interaction terms. The data are an unbalanced quarterly panel of 283 metropolitan areas from 1975, Q3 to 2014, Q2. The aggregate stock returns are contemporaneous (columns 1-3) and 2-quarter lagged (columns 4-6). In columns 3 and 6, the coefficients are estimated for each population tertile of the metropolitan areas by using dummy variables for the medium-sized and small metropolitan areas. The year fixed effects are included in columns 2, 3, 5, and 6 . The standard errors adjusted for heteroskedasticity and clustering at the metropolitan area level are reported in parentheses. The statistical significance is denoted by $* * *, * *$, and $*$ at the $1 \%, 5 \%$, and $10 \%$ level, respectively. 


\begin{tabular}{|c|c|c|c|c|c|c|}
\hline $\begin{array}{l}\text { DEPENDENT VARIABLE: } \\
\text { HPI Growth Rate }\end{array}$ & $(1)$ & $(2)$ & $(3)$ & $(4)$ & $(5)$ & $(6)$ \\
\hline Stock Return (CRSP VW Index) & $\begin{array}{l}0.014^{* * *} \\
(0.002)\end{array}$ & $\begin{array}{l}-0.005^{* *} \\
(0.002)\end{array}$ & $\begin{array}{l}-0.002 \\
(0.002)\end{array}$ & $\begin{array}{l}0.036^{* * *} \\
(0.002)\end{array}$ & $\begin{array}{l}0.030^{* * *} \\
(0.002)\end{array}$ & $\begin{array}{l}0.031^{* * *} \\
(0.003)\end{array}$ \\
\hline$\times \mathrm{D}($ Medium MSAs $)$ & & & $\begin{array}{l}-0.005 \\
(0.006)\end{array}$ & & & $\begin{array}{l}0.003 \\
(0.005)\end{array}$ \\
\hline$\times \mathrm{D}($ Small MSAs $)$ & & & $\begin{array}{l}-0.018^{* * *} \\
(0.006)\end{array}$ & & & $\begin{array}{l}-0.014^{*} \\
(0.008)\end{array}$ \\
\hline Supply Elasticity & $\begin{array}{l}-0.003^{* * *} \\
(0.000)\end{array}$ & $\begin{array}{l}-0.002^{* * *} \\
(0.000)\end{array}$ & $\begin{array}{l}-0.002^{* * *} \\
(0.000)\end{array}$ & $\begin{array}{l}-0.003^{* * *} \\
(0.000)\end{array}$ & $\begin{array}{l}-0.002^{* * *} \\
(0.000)\end{array}$ & $\begin{array}{l}-0.002^{* * *} \\
(0.000)\end{array}$ \\
\hline$\times \mathrm{D}($ Medium MSAs $)$ & & & $\begin{array}{l}-0.001 \\
(0.001)\end{array}$ & & & $\begin{array}{l}-0.001 \\
(0.001)\end{array}$ \\
\hline$\times \mathrm{D}($ Small MSAs $)$ & & & $\begin{array}{l}0.001^{*} \\
(0.001)\end{array}$ & & & $\begin{array}{l}0.001^{*} \\
(0.001)\end{array}$ \\
\hline Stock Return $\times$ Supply Elasticity & $\begin{array}{l}-0.015^{* * *} \\
(0.003)\end{array}$ & $\begin{array}{l}-0.017^{* * *} \\
(0.003)\end{array}$ & $\begin{array}{l}-0.017^{* * *} \\
(0.003)\end{array}$ & $\begin{array}{l}-0.013^{* * *} \\
(0.002)\end{array}$ & $\begin{array}{l}-0.015^{* * *} \\
(0.003)\end{array}$ & $\begin{array}{l}-0.015^{* * *} \\
(0.004)\end{array}$ \\
\hline$\times \mathrm{D}($ Medium MSAs $)$ & & & $\begin{array}{l}0.003 \\
(0.008)\end{array}$ & & & $\begin{array}{l}-0.001 \\
(0.007)\end{array}$ \\
\hline$\times \mathrm{D}($ Small MSAs $)$ & & & $\begin{array}{l}0.012^{*} \\
(0.007)\end{array}$ & & & $\begin{array}{l}0.010 \\
(0.007)\end{array}$ \\
\hline Constant & $\begin{array}{l}0.011^{* * *} \\
(0.000)\end{array}$ & $\begin{array}{l}0.011^{* * *} \\
(0.000)\end{array}$ & $\begin{array}{l}0.011^{* * *} \\
(0.000)\end{array}$ & $\begin{array}{l}0.010^{* * *} \\
(0.000)\end{array}$ & $\begin{array}{l}0.010^{* * *} \\
(0.000)\end{array}$ & $\begin{array}{l}0.010^{* * *} \\
(0.000)\end{array}$ \\
\hline D(Medium MSAs) & & & $\begin{array}{l}0.000 \\
(0.000)\end{array}$ & & & $\begin{array}{l}0.000 \\
(0.001)\end{array}$ \\
\hline D(Small MSAs) & & & $\begin{array}{l}0.000 \\
(0.001)\end{array}$ & & & $\begin{array}{l}0.000 \\
(0.001)\end{array}$ \\
\hline Number of Lags in TFP Growth & 1 quarter & 1 quarter & 1 quarter & 3 quarters & 3 quarters & 3 quarters \\
\hline Year f.e. & No & Yes & Yes & No & Yes & Yes \\
\hline Observations & 36,717 & 36,717 & 36,717 & 36,715 & 36,715 & 36,715 \\
\hline $\mathrm{F}$ & 53.32 & 72.58 & 30.54 & 163.4 & 88.43 & 33.98 \\
\hline Adjusted R-squared & 0.00565 & 0.140 & 0.140 & 0.0122 & 0.140 & 0.141 \\
\hline
\end{tabular}

Table VIII: Home Price Growth and an Alternative Stock Return

This table presents the results from the regressions of the quarterly home price growth rate (FHFA all-transaction HPI) on the aggregate stock returns (NYSE composite index), the log housing supply elasticity (estimated by Saiz, 2010), and their interaction terms. The data are an unbalanced quarterly panel of 283 metropolitan areas from 1975, Q3 to 2014, Q2. The aggregate stock returns are contemporaneous (columns 1-3) and 2-quarter lagged (columns 4-6). In columns 3 and 6, the coefficients are estimated for each population tertile of the metropolitan areas by using dummy variables for the medium-sized and small metropolitan areas. The year fixed effects are included in columns 2, 3, 5, and 6 . The standard errors adjusted for heteroskedasticity and clustering at the metropolitan area level are reported in parentheses. The statistical significance is denoted by $* * *, * *$, and $*$ at the $1 \%, 5 \%$, and $10 \%$ level, respectively. 


\begin{tabular}{|c|c|c|c|c|}
\hline $\begin{array}{l}\text { DEPENDENT VARIABLE: } \\
\text { Standardized HPI Growth Rate }\end{array}$ & (1) & $(2)$ & (3) & $(4)$ \\
\hline Supply Inelasticity Measure & $\begin{array}{l}0.004^{* * *} \\
(0.001)\end{array}$ & $\begin{array}{l}0.005^{* * *} \\
(0.001)\end{array}$ & $\begin{array}{l}0.001^{* * *} \\
(0.000)\end{array}$ & $\begin{array}{l}0.001^{* * *} \\
(0.000)\end{array}$ \\
\hline TFP Growth & $\begin{array}{l}-0.140^{* * *} \\
(0.037)\end{array}$ & & $\begin{array}{l}0.024 \\
(0.024)\end{array}$ & \\
\hline TFP Growth $\times$ Supply Inelasticity Measure & $\begin{array}{l}0.619 * * * \\
(0.104)\end{array}$ & & $\begin{array}{l}0.173^{* * *} \\
(0.023)\end{array}$ & \\
\hline Stock Return (NYSE Composite) & & $\begin{array}{l}-0.030^{* * *} \\
(0.003)\end{array}$ & & $\begin{array}{l}-0.018^{* * *} \\
(0.002)\end{array}$ \\
\hline Stock Return $\times$ Supply Inelasticity Measure & & $\begin{array}{l}0.044^{* * *} \\
(0.009)\end{array}$ & & $\begin{array}{l}0.013^{* * *} \\
(0.003)\end{array}$ \\
\hline Constant & $\begin{array}{l}0.008^{* * *} \\
(0.000)\end{array}$ & $\begin{array}{l}0.008^{* * *} \\
(0.000)\end{array}$ & $\begin{array}{l}0.009 * * * \\
(0.000)\end{array}$ & $\begin{array}{l}0.009 * * * \\
(0.000)\end{array}$ \\
\hline Supply Inelasticity Measure & \multicolumn{2}{|c|}{ Share Unavailable } & \multicolumn{2}{|c|}{ WRLURI } \\
\hline Year f.e. & Yes & Yes & Yes & Yes \\
\hline Observations & 36,717 & 36,717 & 36,717 & 36,717 \\
\hline $\mathrm{F}$ & 38.32 & 59.41 & 36.57 & 60.67 \\
\hline Adjusted R-squared & 0.138 & 0.138 & 0.138 & 0.138 \\
\hline
\end{tabular}

Table IX: Estimation Using Alternative Measures of Supply Elasticity

This table presents the regression results on the basis of alternative measures of housing supply (in)elasticity. These are the Share Unavailable for Development produced by Saiz $(2010)$ for columns 1 and 2 and the Wharton Residential Land Use Regulation Index developed by Gyourko, Saiz, and Summers (2008) for columns 3 and 4. Both measures represent the inelastic supply of housing. The dependent variable is the quarterly home price growth rate. The regressors are the supply (in)elasticity measure, the TFP growth (columns 1 and 3), the stock returns (columns 2 and 4), and their interaction terms. The data are an unbalanced quarterly panel of 283 metropolitan areas from 1975, Q3 to 2014, Q2. The volatility of the home price growth rates is normalized to unity for each metropolitan area. The year fixed effects are included in all models. The standard errors adjusted for heteroskedasticity and clustering at the metropolitan area level are reported in parentheses. The statistical significance is denoted by $* * *, * *$, and $*$ at the $1 \%, 5 \%$, and $10 \%$ level, respectively. 
Panel A: Quarterly OECD Country Panel

\begin{tabular}{lrrrrr}
\hline & \multicolumn{5}{c}{18 Countries, N: 2,946} \\
VARIABLES & Mean & Median & S.D. & Min. & Max. \\
\hline & & & & & \\
Quarterly log home price change & 0.0153 & 0.0135 & 0.0241 & -0.0939 & 0.125 \\
Quarterly stock return & 0.0173 & 0.0235 & 0.0890 & -0.510 & 0.416 \\
Population in 2005 (1000's) & 49,531 & 20,329 & 71,010 & 4,099 & 296,410 \\
Urban population (1000's, city population $>$ 500K) & 24,319 & 13,423 & 42,494 & 975 & 173,098 \\
Land Area (kha) & 176,861 & 30,389 & 323,943 & 3,028 & 914,742 \\
Habitable Area (kha) & 111,716 & 17,639 & 209,205 & 2,229 & 614,886 \\
Urban Land (kha, city population $>500 \mathrm{~K})$ & 13,269 & 3,832 & 33,543 & 290 & 144,298 \\
Per Capita habit area (ha) & 3.731 & 0.670 & 7.667 & 0.079 & 30.250 \\
Per Capita urban land (ha) & 0.041 & 0.037 & 0.016 & 0.021 & 0.083 \\
Log per Capita habit area & -0.086 & -0.400 & 1.567 & -2.536 & 3.409 \\
Log per Capita urban land & 5.944 & 5.908 & 0.370 & 5.352 & 6.726 \\
\hline
\end{tabular}

Panel B: Annual OECD Country Panel

\begin{tabular}{lrrrrr}
\hline & \multicolumn{5}{c}{18 Countries, N $=737$} \\
VARIABLES & Mean & Median & S.D. & Min. & Max. \\
\hline & & & & & \\
Annual log home price change & 0.0663 & 0.0611 & 0.0814 & -0.212 & 0.371 \\
Annual change in TFP at constant national prices & 0.0028 & 0.0040 & 0.016 & -0.081 & 0.054 \\
Population in 2005 (1000's) & 47,137 & 16,320 & 69,071 & 4,099 & 296,410 \\
Urban population (1000's, city population $>$ 500K) & 23,001 & 4,954 & 41,246 & 975 & 173,098 \\
Land Area (kha) & 165,565 & 30,389 & 314,472 & 3,028 & 914,742 \\
Habitable Area (kha) & 104,615 & 17,639 & 202,999 & 2,229 & 614,886 \\
Urban Land (kha, city population $>500 \mathrm{~K})$ & 12,420 & 1,774 & 32,438 & 290 & 144,298 \\
Per Capita habit area (ha) & 3.587 & 0.670 & 7.421 & 0.0792 & 30.25 \\
Per Capita urban land (ha) & 0.040 & 0.037 & 0.016 & 0.021 & 0.083 \\
Log per Capita habit area & -0.090 & -0.400 & 1.543 & -2.536 & 3.409 \\
Log per Capita urban land & 5.933 & 5.908 & 0.367 & 5.352 & 6.726 \\
\hline
\end{tabular}

Table X: Descriptive Statistics of Cross-Country Data 


\begin{tabular}{|c|c|c|c|c|c|}
\hline $\begin{array}{l}\text { DEPENDENT VARIABLE: } \\
\text { Standardized HPI Growth Rate }\end{array}$ & (1) & $(2)$ & $(3)$ & (4) & $(5)$ \\
\hline Standardized TFP Growth & $\begin{array}{c}0.215^{* * *} \\
(0.033)\end{array}$ & $\begin{array}{c}1.103^{* *} \\
(0.458)\end{array}$ & $\begin{array}{l}0.731^{* *} \\
(0.336)\end{array}$ & $\begin{array}{c}0.212^{* * *} \\
(0.029)\end{array}$ & $\begin{array}{c}0.224^{* * *} \\
(0.033)\end{array}$ \\
\hline $\begin{array}{l}\text { Standardized TFP Growth } \\
\quad \times \text { Supply Elasticity Measure }\end{array}$ & & $\begin{array}{r}-0.150^{*} \\
(0.075)\end{array}$ & $\begin{array}{l}-0.085 \\
(0.057)\end{array}$ & $\begin{array}{c}-0.039 * * * \\
(0.013)\end{array}$ & $\begin{array}{c}-0.044^{* *} \\
(0.017)\end{array}$ \\
\hline Supply Elasticity Measure & & $\begin{array}{c}0.001 \\
(0.003)\end{array}$ & $\begin{array}{c}0.000 \\
(0.003)\end{array}$ & $\begin{array}{c}0.002 \\
(0.001)\end{array}$ & $\begin{array}{c}0.002 \\
(0.001)\end{array}$ \\
\hline Constant & $\begin{array}{c}0.004 \\
(0.003)\end{array}$ & $\begin{array}{c}0.006^{* *} \\
(0.003)\end{array}$ & $\begin{array}{c}0.006^{* *} \\
(0.002)\end{array}$ & $\begin{array}{l}-0.003 \\
(0.003)\end{array}$ & $\begin{array}{l}-0.003 \\
(0.003)\end{array}$ \\
\hline Supply Elasticity Measure & - & \multicolumn{2}{|c|}{ Log per capita urban land } & \multicolumn{2}{|c|}{ Log per capita habitable area } \\
\hline Year f.e. & No & No & Yes & No & Yes \\
\hline Observations & 736 & 736 & 736 & 736 & 736 \\
\hline $\mathrm{F}$ & 43.36 & 17.41 & 14.92 & 24.11 & 17.50 \\
\hline Adjusted R-squared & 0.0464 & 0.0469 & 0.327 & 0.0475 & 0.331 \\
\hline
\end{tabular}

Table XI: Home Price Growth and TFP Growth, Annual Panel of OECD Countries

This table presents the result for the regressions of the annual growth rate of the standardized housing prices (with unit variance). The regressors are the standardized TFP growth rate (1-year lagged), the housing supply elasticity, and their interaction term. The housing supply elasticity measures are the logarithm of the per capita urban land (columns 2-3) and the logarithm of the per capita habitable area (columns 4-5). The urban area is defined as cities with a population greater than 500,000. The habitable area is defined as the national land area minus the inland water, forest, and woodland. The data are an unbalanced annual panel of 18 OECD countries between 1971 and 2011. In columns 3 and 5, the year fixed effects are included. The standard errors adjusted for heteroskedasticity and clustering at the country level are reported in parentheses. The statistical significance is denoted by $* * *, * *$, and $*$ at the $1 \%, 5 \%$, and $10 \%$ level, respectively. 


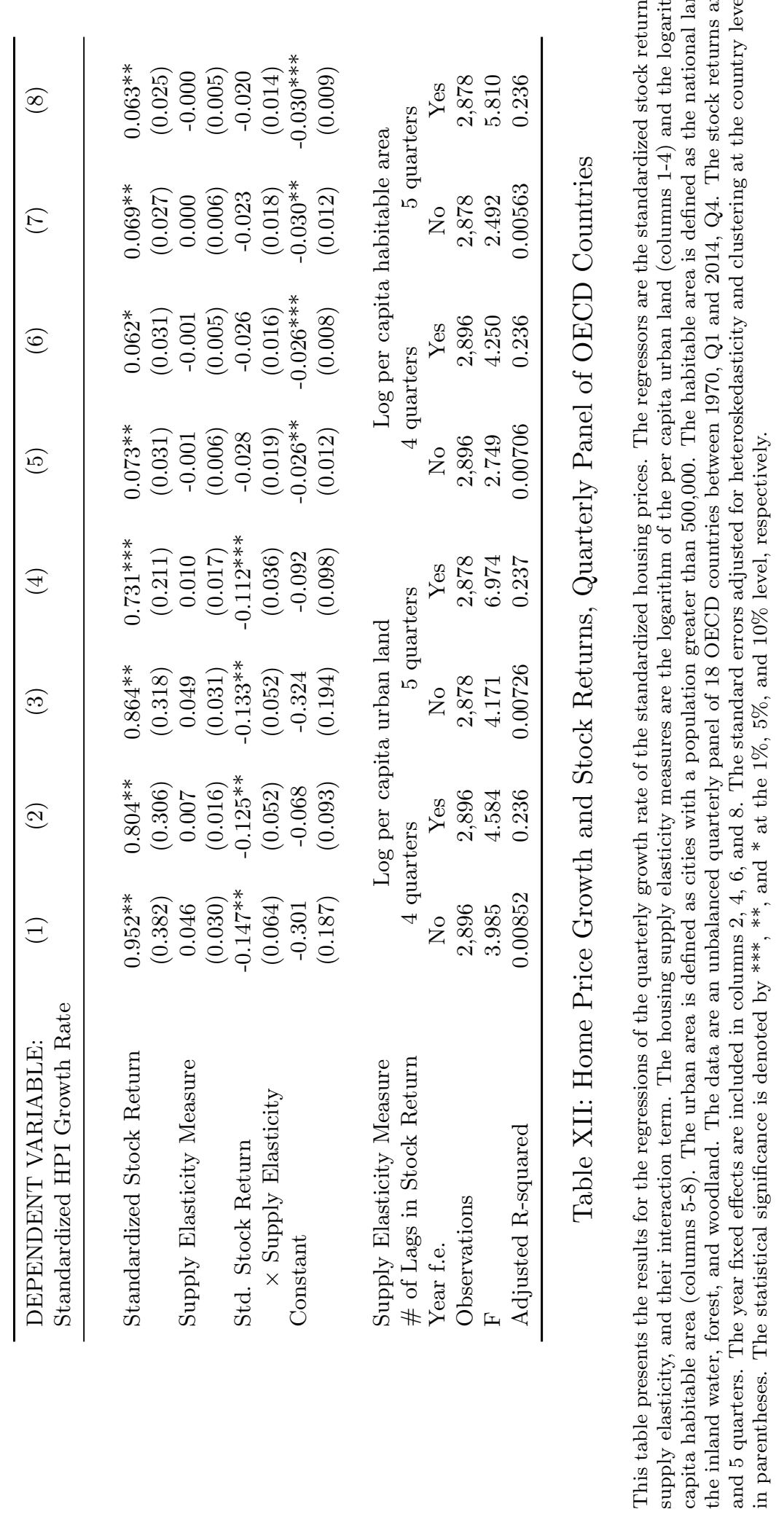




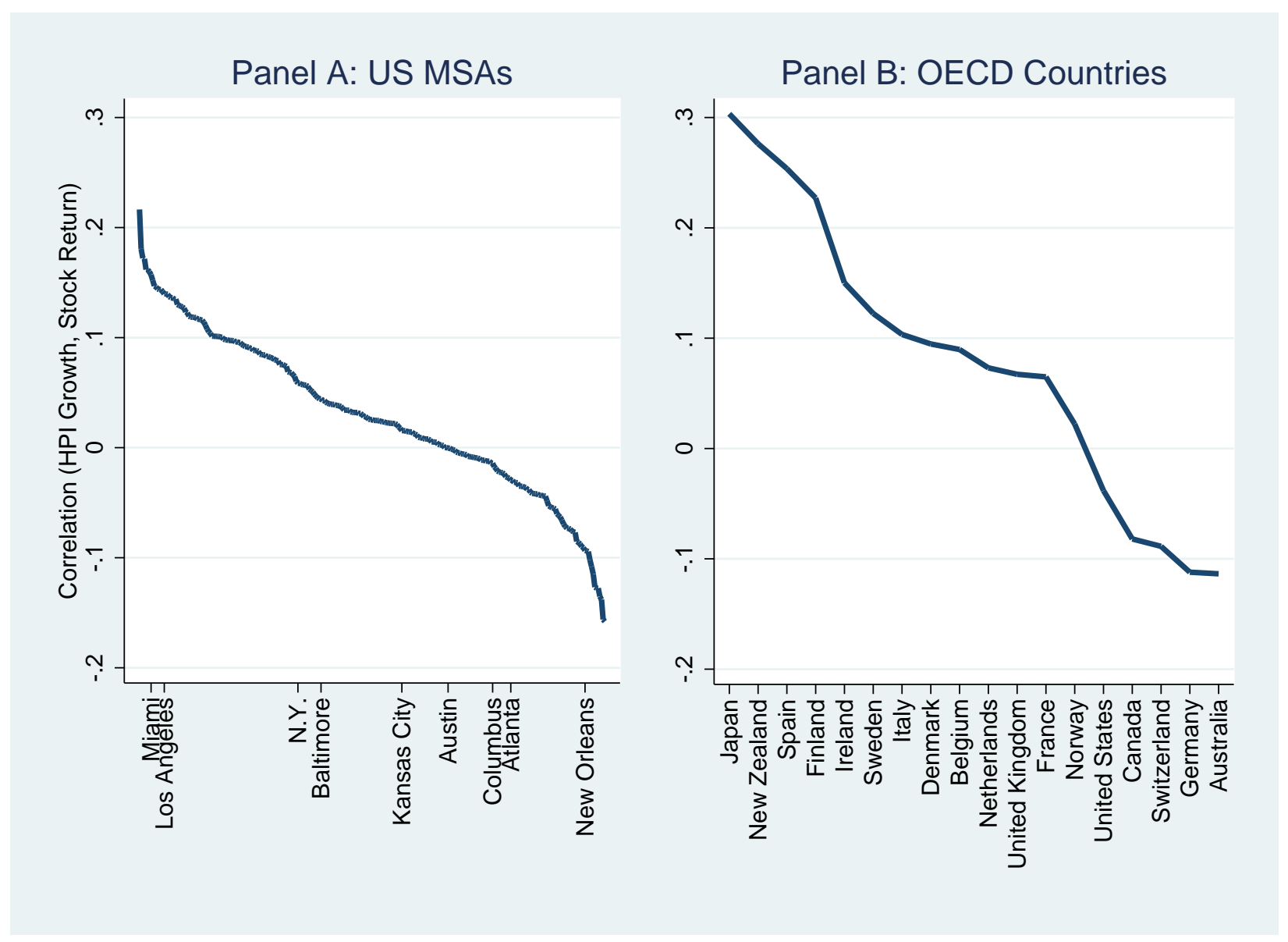

Figure 1: Correlation Coefficients between Home Price Growth and Stock Returns

This figure depicts the correlation coefficient of the quarterly home price growth and the stock returns. The names for the selected MSAs and countries are shown on the horizontal axis. In Panel A, the home price is the FHFA all-transaction quarterly index and the stock price is the contemporaneous NYSE value-weighted quarterly composite index from 1975, Q3 to 2014 , Q2. In Panel B, the national home price index uses BIS calculations based on national data and the stock price index (4-quarter lagged) is obtained from the OECD between 1970, Q1 and 2014, Q4, with a few exceptions. The correlation coefficient is estimated by $\beta+\gamma_{i}$ from panel regressions: $d \ln S H P I_{i t}=\alpha+\beta d \ln S S P_{i t}+\gamma_{i} d \ln S S P_{i t} \times L O C A T I O N_{i}+\delta_{i} L O C A T I O N_{i}+\varepsilon_{i t}$, where $d \ln S H P I_{i t}$ denotes the standardized quarterly housing price growth rate (with unit variance), dlnSSP $P_{i t}$ denotes the standardized quarterly stock return (with unit variance), and LOCATION $N_{i}$ denotes either the MSA or country dummies. The standard errors of the estimated coefficients are negligible. 


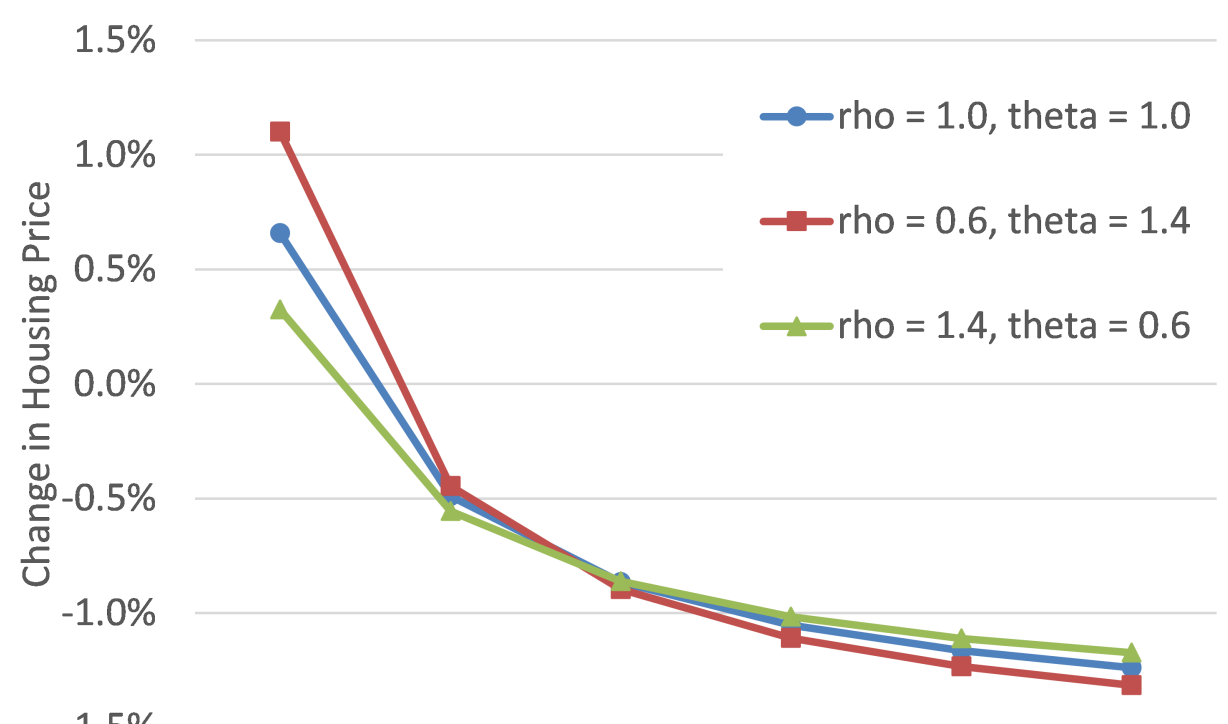

(a) Change in Housing Price

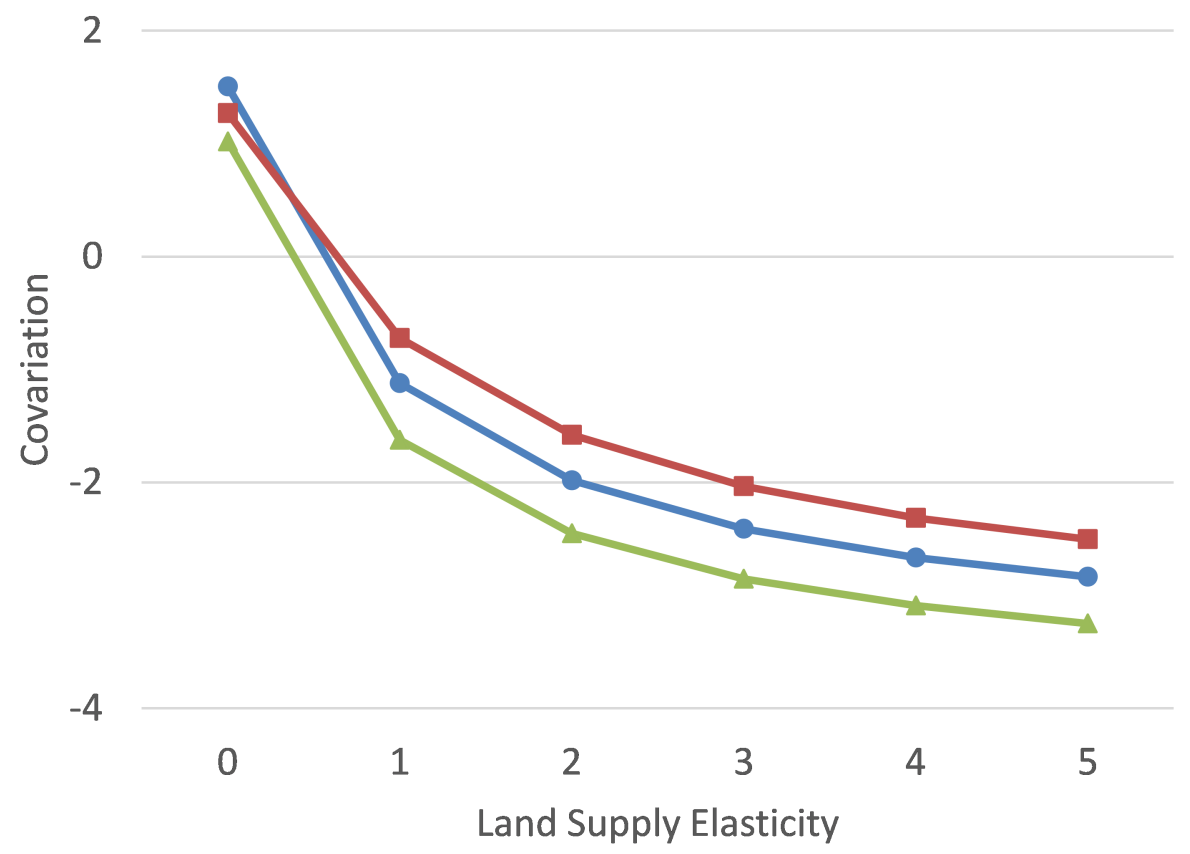

(b) Covariation

Figure 2: The Effect of a Positive Permanent Shock on Asset Prices

This figure depicts the changes in the equilibrium housing price (Panel (a)) and the stock-housing covariation (Panel (b)) due to a permanent technology shock. The land supply elasticity is on the horizontal axis. The covariation is defined by the product of percentage changes in housing prices and a proxy for stock prices. The three graphs correspond to alternative combinations of parameter values for the elasticity of substitution; parameters $\rho$ and $\theta$ denote the intra-temporal and inter-temporal elasticities of substitution, respectively. 


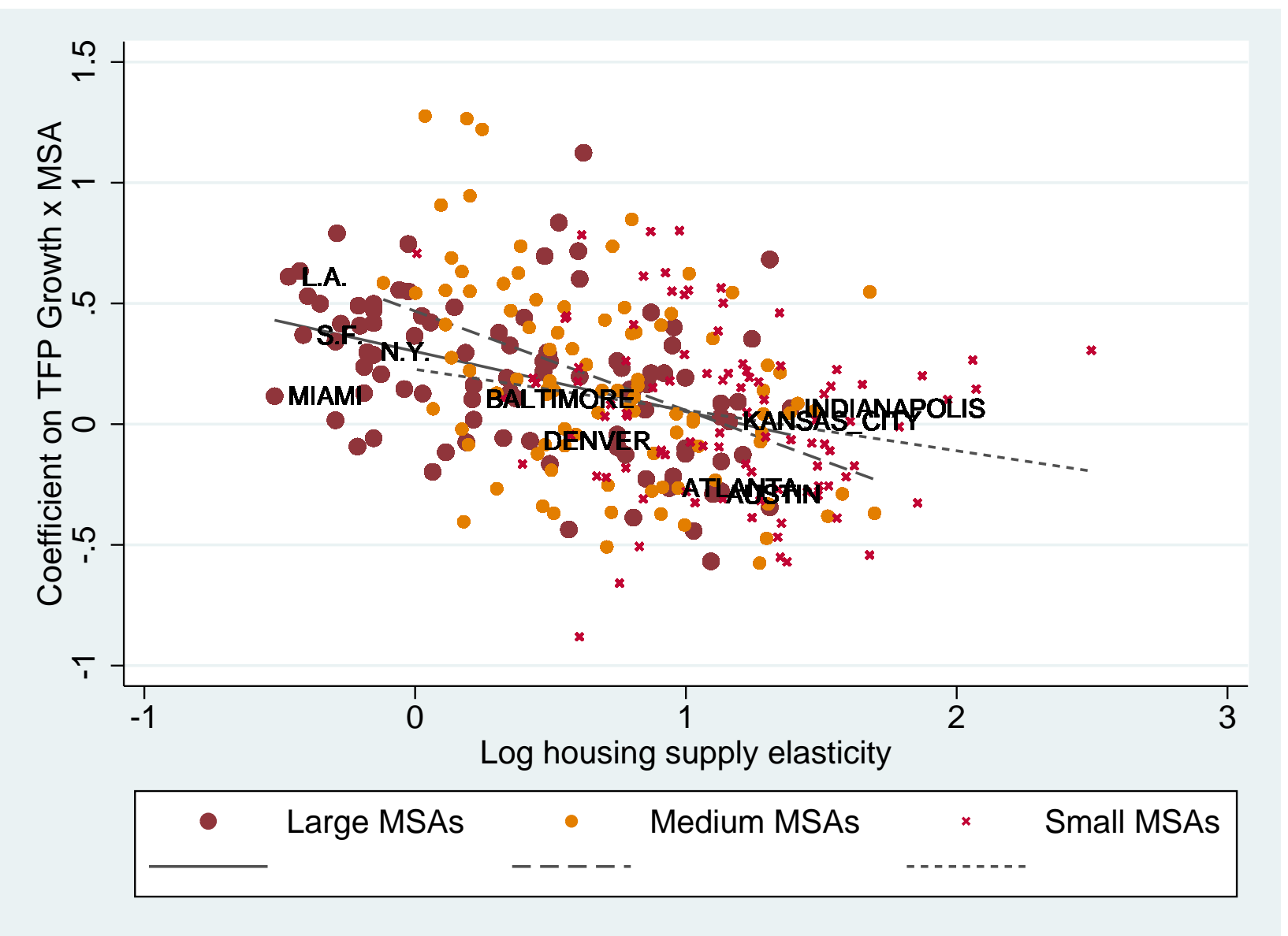

Figure 3: Relationship between Housing Supply Elasticity and the Housing Price Response to TFP Shocks

This figure provides a visualization of the regression results reported in Table $\mathrm{V}$ The vertical axis is the MSA-specific regression coefficient $\beta+\gamma_{i}$ from a model: $d \ln H P I_{i t}=\alpha+\beta d \ln T F P_{t}+\gamma_{i} d \ln T F P_{t} \times M S A_{i}+\delta_{i} M S A_{i}+\varepsilon_{i t}$, where $d \ln H P I_{i t}$ denotes the quarterly housing price growth rate (FHFA all-transaction HPI), $d \ln T F P_{t}$ denotes the quarterly TFP growth rate (estimated by Fernald 2014 and updated on February 06, 2015), and $M S A_{i}$ denotes the MSA dummies. The horizontal axis is the log housing supply elasticity estimated by Saiz (2010). The data are an unbalanced quarterly panel of 264 MSAs between 1975 , Q3 and 2014, Q2, categorized by population tertiles. The names of selected large MSAs are shown next to the relevant plots. 


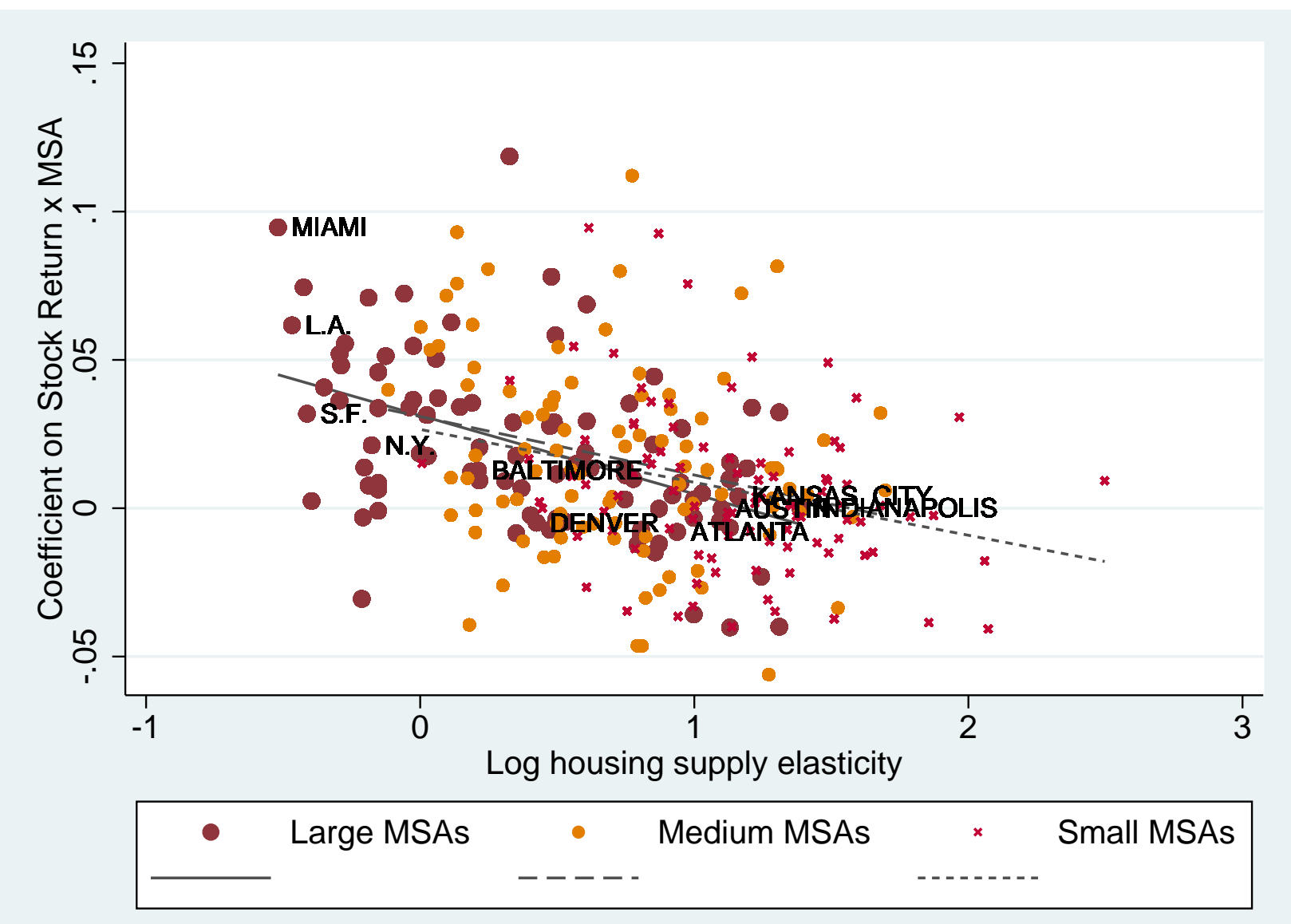

Figure 4: Relationship between Housing Supply Elasticity and the Stock-Housing Correlations

This figure provides a visualization of the regression results reported in Table VII The vertical axis is the MSA-specific regression coefficient $\beta+\gamma_{i}$ from a model: $d \ln H P I_{i t}=\alpha+\beta d \ln S P_{t}+\gamma_{i} d \ln S P_{t} \times M S A_{i}+\delta_{i} M S A_{i}+\varepsilon_{i t}$, where $d \ln H P I_{i t}$ denotes the quarterly housing price growth rate (FHFA all-transaction HPI), $d \ln S P_{t}$ denotes the quarterly stock return (NYSE composite index), and $M S A_{i}$ denotes the MSA dummies. The horizontal axis is the log housing supply elasticity estimated by Saiz (2010). The data are an unbalanced quarterly panel of 264 MSAs between 1975, Q3 and 2014, Q2, categorized by the population tertiles. The names of selected large MSAs are shown next to the relevant plots. 

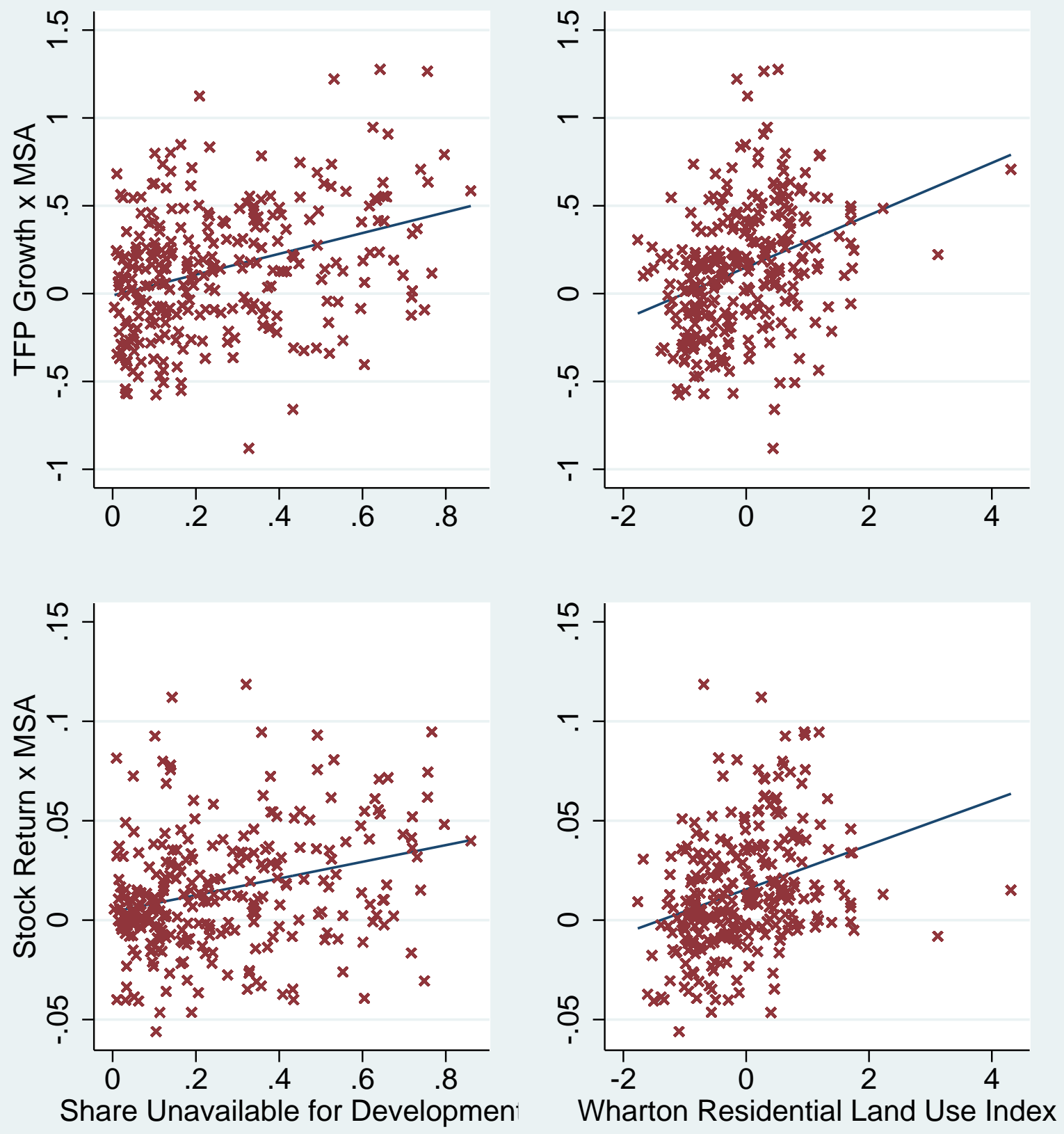

Figure 5: Relationships with Alternative Measures of Housing Supply Elasticity

This figure provides a visualization of the regression results reported in Table IX The vertical axis is the MSA-specific regression coefficient $\beta+\gamma_{i}$ from the following regressions. For the upper panels, $d \ln H P I_{i t}=\alpha+\beta d \ln T F P_{t}+\gamma_{i} d \ln T F P_{t} \times M S A_{i}+$ $\delta_{i} M S A_{i}+\varepsilon_{i t}$, where $d \ln H P I_{i t}$ denotes the quarterly housing price growth rate (FHFA all-transaction HPI), $d l n T F P_{t}$ denotes the quarterly TFP growth rate (estimated by Fernald, 2014 and updated on February 06, 2015), and $M S A_{i}$ denotes the dummies for 264 MSAs. For the lower panels, $d \ln T F P_{t}$ is replaced by $d \ln S P_{t}$, which denotes the quarterly stock return (NYSE composite). The horizontal axis is the Share Unavailable for Development produced by Saiz (2010) for the left panels and the Wharton Regulation Index developed by Gyourko, Saiz, and Summers (2008) for the right panels. Both measures represent the inelastic supply of housing. 


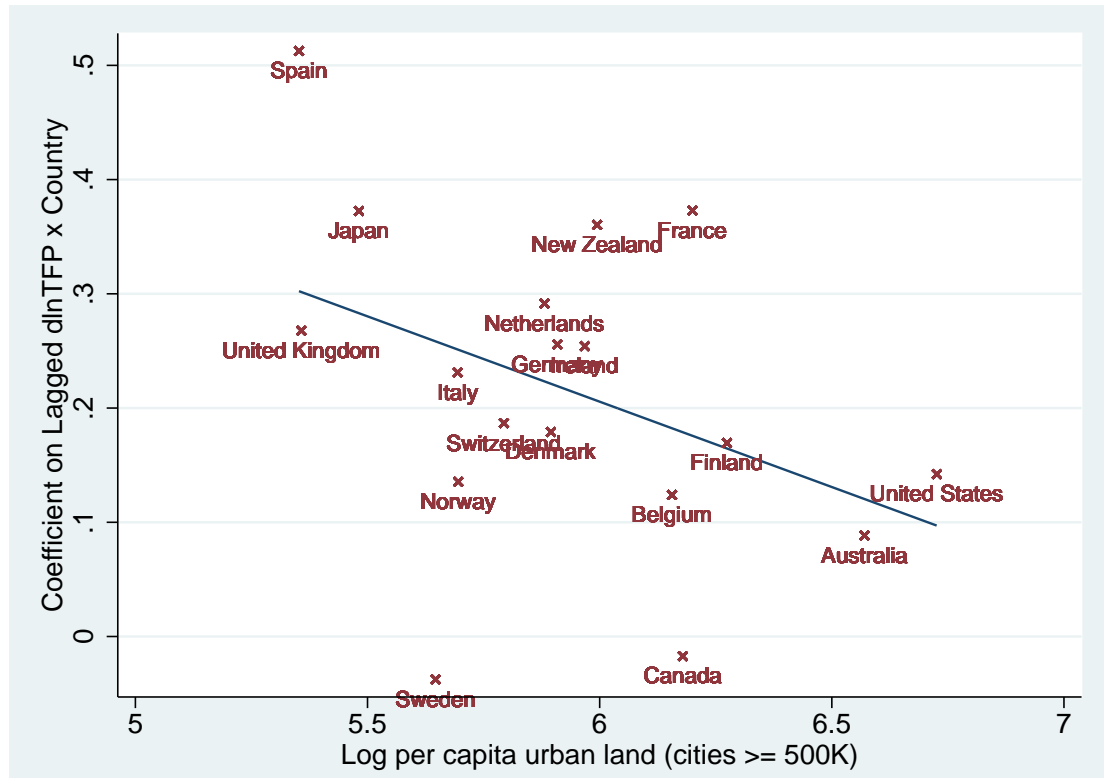

(a) Land supply elasticity: Log per capita urban land

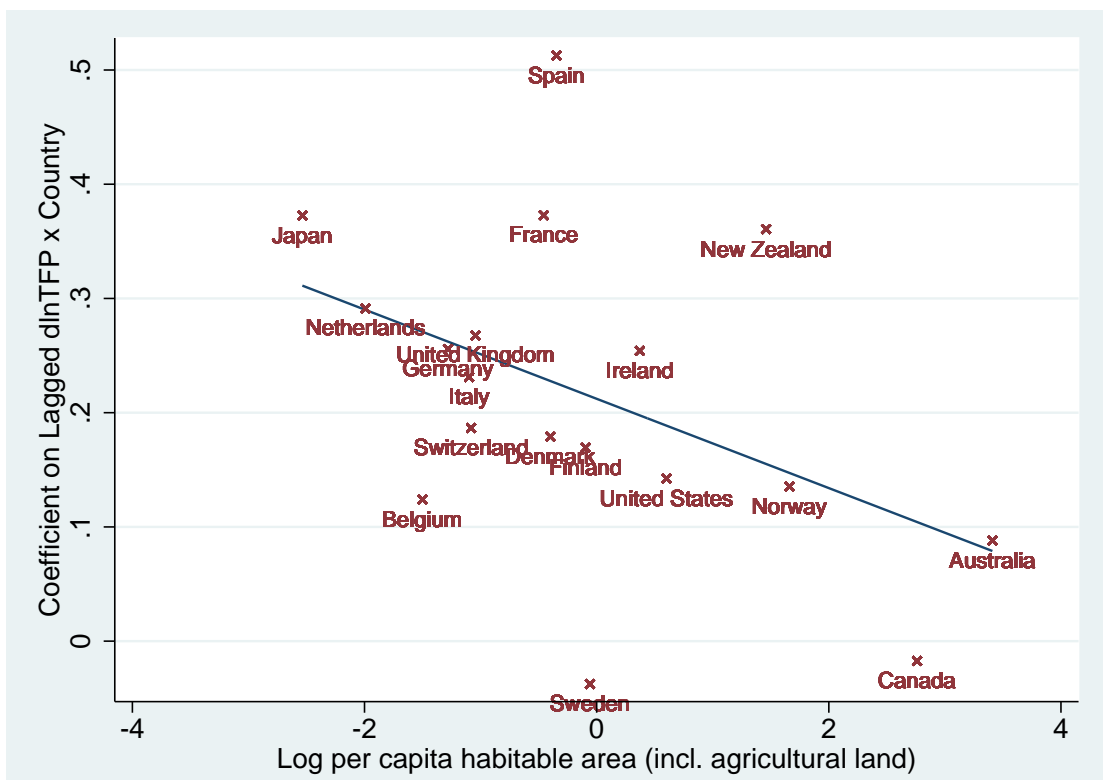

(b) Land supply elasticity: Log per capita habitable area

Figure 6: Relationship between Land Supply Elasticity and the Housing Price Response to TFP Shocks at the Country Level

This figure depicts the regression results reported in Table XI The vertical axis is the country-specific regression coefficient $\beta+\gamma_{i}$ from a regression: $d \ln S H P I_{i t}=\alpha+\beta d \ln S T F P_{i, t-1}+\gamma_{i} d \ln S T F P_{i, t-1} \times C O U N T R Y_{i}+\delta_{i} C O U N T R Y_{i}+\varepsilon_{i t}$, where $d \ln S H P I_{i t}$ denotes the standardized annual housing price growth rate (with unit variance), $\operatorname{dln} S T F P_{i t}$ denotes the standardized annual TFP growth rate (1-year lagged), and $C O U N T R Y_{i}$ denotes the country dummies. The land supply elasticity measure on the horizontal axis is the log per capita urban land (Panel a) and the log per capita habitable area (Panel b). The data are an unbalanced annual panel of 18 OECD countries between 1971 and 2011. 


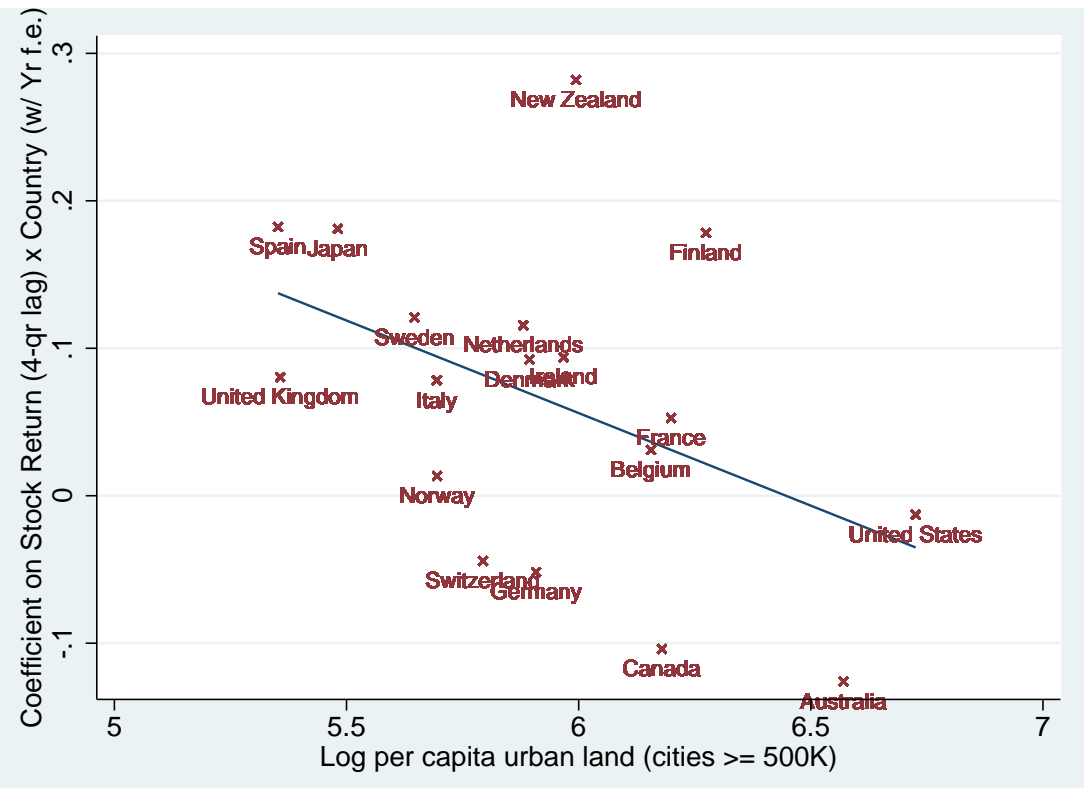

(a) Land supply elasticity: Log per capita urban land

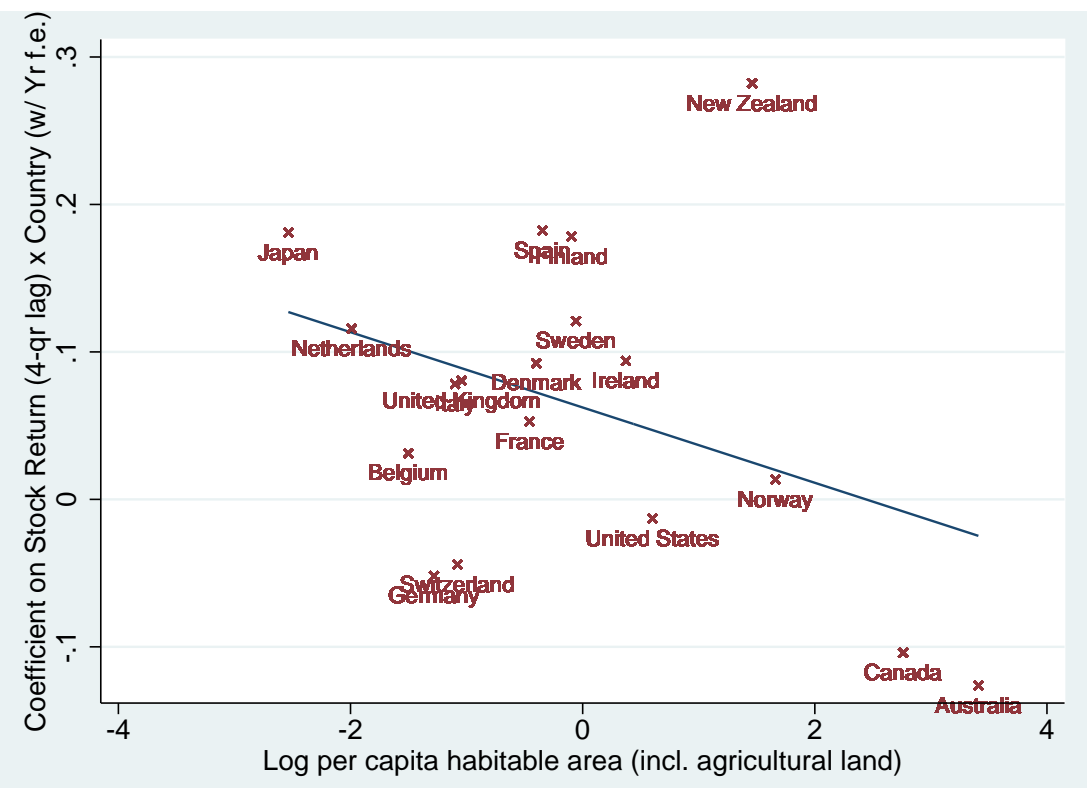

(b) Land supply elasticity: Log per capita habitable area

Figure 7: Relationship between Land Supply Elasticity and the Stock-Housing Correlations at the Country Level

This figure depicts the regression results reported in Table XII The vertical axis is the country-specific regression coefficient $\beta+\gamma_{i}$ from a regression: $d \ln S H P I_{i t}=\alpha+\beta d \ln S S P_{i, t-4}+\gamma_{i} d \ln S S P_{i, t-4} \times C O U N T R Y_{i}+\delta_{i} C O U N T R Y_{i}+\varepsilon_{i t}$, where $d l n S H P I_{i t}$ denotes the standardized quarterly housing price growth rate (with unit variance), $d \ln S S P_{i t}$ denotes the standardized quarterly stock return (with unit variance), and COUNTRY $Y_{i}$ denotes the country dummies. The land supply elasticity measure is on the horizontal axis. The data are an unbalanced quarterly panel of 18 OECD countries between 1970, Q1 and 2014 , Q4. 


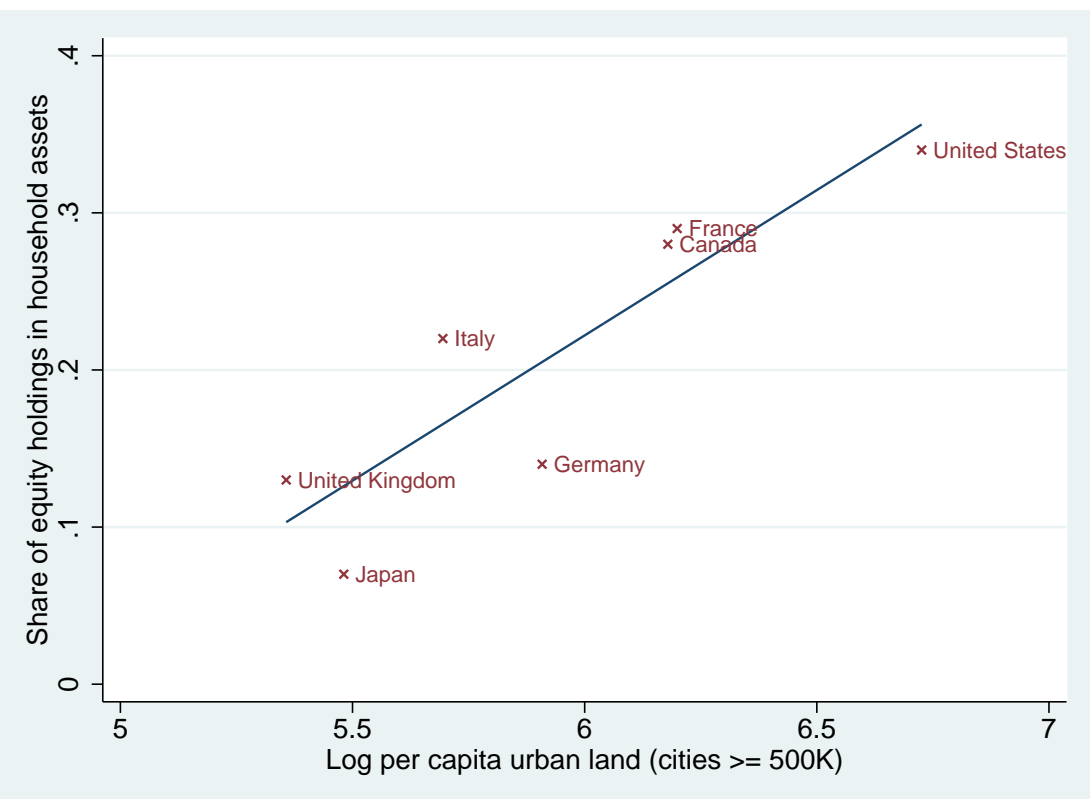

(a) Land supply elasticity: Log per capita urban land

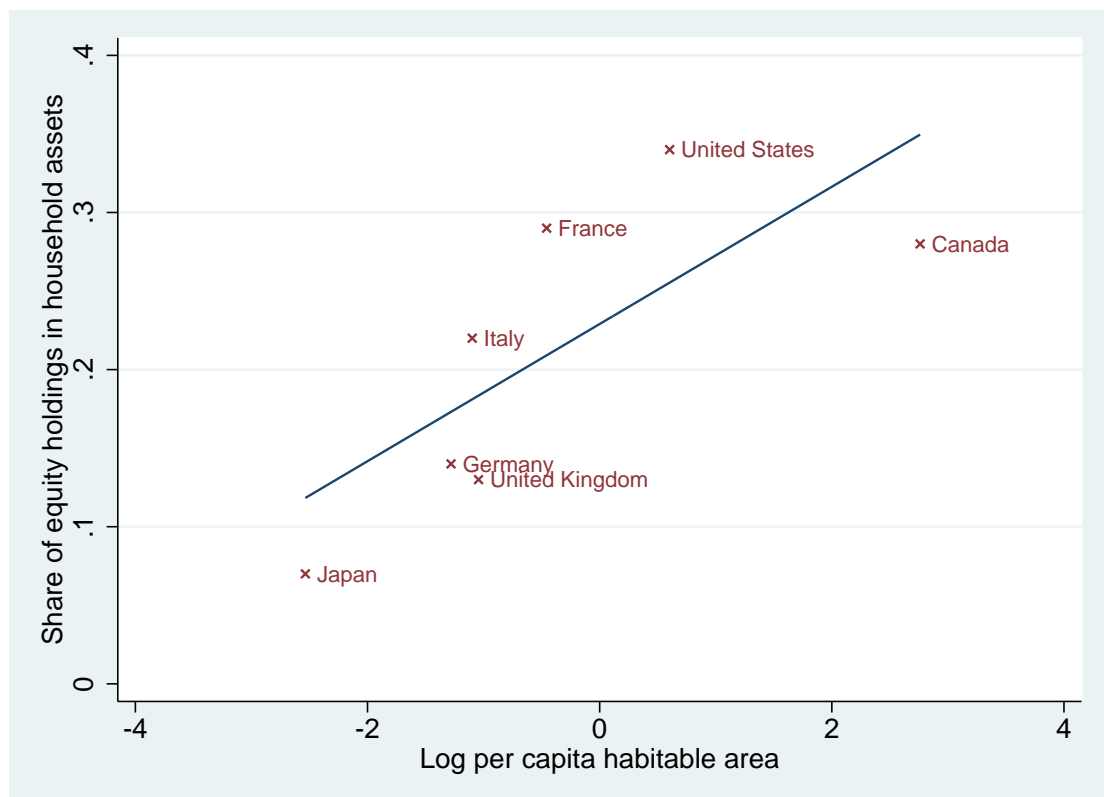

(b) Land supply elasticity: Log per capita habitable area

Figure 8: Relationship between the Share of Equity Holdings and Land Supply Elasticity

This figure depicts the share of equity holdings in household assets at the end of 2001 plotted against the land supply elasticity measure for seven OECD countries. The land supply elasticity measure on the horizontal axis is the log per capita urban land (Panel (a)) and the log per capita habitable area (Panel (b)). The equity share data are obtained from Bank of Japan (2003). 


\section{Appendix A Derivation of the Equilibrium}

In this appendix, I describe how to solve for the equilibrium that is defined in the paper.

Let $\phi_{t, t+1} \equiv 1 / i_{t}$ denote the discount factor for time $t+1$ as of time $t$. The price of any asset is expressed as future returns in units of the numeraire multiplied by the discount factor. Equations (7), (9), and (12) imply that the discount factor is expressed in three different ways:

$$
\begin{array}{rlr}
\phi_{1,2} & =\left[1+\frac{\partial Y_{2}}{\partial K_{2}}-\delta\right]^{-1} & \text { (Reciprocal of MPK) } \\
& =\left[1+p_{2} \frac{\partial H_{2}}{\partial S_{2}}-\delta\right]^{-1} & \text { (Reciprocal of MPHS) } \\
& =\beta \frac{\partial u / \partial C_{2}}{\partial u / \partial C_{1}} & \text { (IMRS) }
\end{array}
$$

Equations (A.1) and (A.2) are used for analyzing goods-sector shocks and housing shocks, respectively.

Now, I rewrite the dynamic budget constraints as the lifetime budget constraint to define the lifetime income, Inc:

$$
\begin{aligned}
C_{1}+p_{1} H_{1}+\frac{1}{i_{2}}\left(C_{2}+p_{2} H_{2}\right) & =i_{1} W_{0}+r_{1} T_{1}+w_{1}+\frac{1}{i_{2}}\left(r_{2} T_{2}+w_{2}\right) \\
& \equiv \text { Inc. }
\end{aligned}
$$

Then the consumption demands are derived as a function of Inc: ${ }^{19}$

$$
\begin{aligned}
C_{1} & =\left(1+p_{1}^{1-\rho}\right)^{-1}\left[1+\beta^{\theta} i_{2}^{-(1-\theta)}\left(\frac{1+p_{2}^{1-\rho}}{1+p_{1}^{1-\rho}}\right)^{\frac{1-\theta}{1-\rho}}\right]^{-1} \text { Inc, } \\
C_{2} & =\beta^{\theta} i_{2}^{\theta}\left(\frac{1+p_{2}^{1-\rho}}{1+p_{1}^{1-\rho}}\right)^{\frac{\rho-\theta}{1-\rho}} C_{1}, \\
H_{t}^{\text {dem }} & =\frac{C_{t}}{p_{t}^{\rho}}
\end{aligned}
$$

Note that the housing rents have an effect on the consumption demand in general whereas they have no effect in the log utility case. It is also clear that the expenditure ratio of housing, $p_{t} H_{t} / C_{t}$,

\footnotetext{
${ }^{19}$ In the log-utility case, they reduce to $C_{1}=\operatorname{Inc} /[2(1+\beta)], C_{2}=\beta i_{2} C_{1}$, and $H_{t}^{\text {dem }}=C_{t} / p_{t}$.
} 
equals $p_{t}^{1-\rho}$ in general whereas it is always 1 in the log case.

(Labor markets) Labor supply is $L_{t}^{\text {sup }}=1$. Labor demand is derived from the first-order condition of a goods-producing firm (8): $w_{t}=(1-\alpha) A_{t}\left(K_{t} / L_{t}\right)^{\alpha}$. Using the capital demand from another first-order condition (7), the equilibrium wage is derived as a function of $A_{t}$ and $i_{t}$ :

$$
w_{t}^{e q}\left(A_{t}, i_{t}\right)=(1-\alpha) \alpha^{\frac{\alpha}{1-\alpha}} A_{t}^{\frac{1}{1-\alpha}}\left(i_{t}-1+\delta\right)^{-\frac{\alpha}{1-\alpha}} .
$$

(Land markets) Land supply is $T_{t}=r_{t}^{\mu}$. Land demand is derived from the first-order condition of a real estate firm (10): $T_{t}^{\text {dem }}=\left\{(1-\gamma) B_{t} p_{t} / r_{t}\right\}^{\frac{1}{\gamma}} S_{t}$. Using demand for housing structures from another first-order condition $(99)$, the equilibrium land rent and the quantity of land is derived as a function of $B_{t}, p_{t}, i_{t}$ :

$$
\begin{aligned}
& r_{t}^{e q}\left(B_{t}, p_{t}, i_{t}\right)=\gamma^{\frac{\gamma}{1-\gamma}}(1-\gamma) B_{t}^{\frac{1}{1-\gamma}} p_{t}^{\frac{1}{1-\gamma}}\left(i_{t}-1+\delta\right)^{-\frac{\gamma}{1-\gamma}} \\
& T_{t}^{e q}\left(B_{t}, p_{t}, i_{t}\right)=\gamma^{\frac{\gamma \mu}{1-\gamma}}(1-\gamma)^{\mu} B_{t}^{\frac{\mu}{1-\gamma}} p_{t}^{\frac{\mu}{1-\gamma}}\left(i_{t}-1+\delta\right)^{-\frac{\gamma \mu}{1-\gamma}}
\end{aligned}
$$

Although both $r_{t}$ and $T_{t}$ depend on the housing rent $p_{t}$, it is possible to write $r_{t}$ and $T_{t}$ as functions of $B_{t}, A_{1}, A_{2}, i_{1}, i_{2}$ after deriving the equilibria of the other markets.

(Housing markets) Housing supply is:

$$
H_{t}^{\text {sup }}\left(p_{t} ; B_{t}, i_{t}\right)=B_{t} S_{t}^{e q}\left(B_{t}, p_{t}, i_{t}\right)^{\gamma} \times T_{t}^{e q}\left(B_{t}, p_{t}, i_{t}\right)^{1-\gamma}
$$

Housing demand is derived as A.6 from the first-order conditions of the households. Analytical solution to the housing market equilibrium is available for the log case:

$$
\begin{gathered}
p_{1}^{e q}\left(i_{1}, \text { Inc }\right)=\{2(1+\beta)\}^{-\frac{1-\gamma}{1+\mu}} \gamma^{-\gamma}(1-\gamma)^{-\frac{\mu(1-\gamma)}{1+\mu}} B_{1}^{-1}\left(i_{1}-1+\delta\right)^{\gamma} \operatorname{Inc}^{\frac{1-\gamma}{1+\mu}}, \\
H_{1}^{e q}\left(i_{1}, \text { Inc }\right)=\{2(1+\beta)\}^{-\frac{\gamma+\mu}{1+\mu}} \gamma^{\gamma}(1-\gamma)^{\frac{\mu(1-\gamma)}{1+\mu}} B_{1}\left(i_{1}-1+\delta\right)^{-\gamma} \operatorname{Inc}^{\frac{\gamma+\mu}{1+\mu}}
\end{gathered}
$$

For the CES-CRRA case, a numerical solution must be used to derive $p_{1}$ and $p_{2}$ jointly with $i_{1}$ and $i_{2}$.

(Capital markets) After obtaining $p_{1}^{e q}\left(i_{1}\right.$, Inc) and $H_{1}^{e q}\left(i_{1}\right.$, Inc $)$ for the log case, I can rewrite 
$r_{t}^{e q}\left(i_{t}\right.$, Inc $)$ and $T_{t}^{e q}\left(i_{t}\right.$, Inc $)$ and further derive Inc as:

$$
\begin{aligned}
\operatorname{Inc}\left(A_{1}, A_{2}, i_{1}, i_{2}\right)= & i_{1} W_{0}+r_{1} T_{1}\left(i_{1}, \operatorname{Inc}\right)+w_{1}\left(A_{1}, i_{1}\right) \\
& +\frac{1}{i_{2}}\left\{r_{2} T_{2}\left(i_{2}, \operatorname{Inc}\right)+w_{2}\left(A_{2}, i_{2}\right)\right\} \\
= & 2(1+\gamma)^{-1} \alpha^{\frac{\alpha}{1-\alpha}}(1-\alpha) \\
& \times\left\{A_{1}^{\frac{1}{1-\alpha}}\left(i_{1}-1+\delta\right)^{-\frac{\alpha}{1-\alpha}}+A_{2}^{\frac{1}{1-\alpha}} i_{2}^{-1}\left(i_{2}-1+\delta\right)^{-\frac{\alpha}{1-\alpha}}\right\} .
\end{aligned}
$$

Note that $B_{t}$ does not appear in land rents or land quantity in the log-utility case whereas it does appear in the CES-CRRA case.

Now the capital supply for period $2, W_{1}$, is derived. Given $\operatorname{Inc}\left(A_{1}, A_{2}, i_{1}, i_{2}\right)$, the consumption becomes $C_{t}\left(A_{1}, A_{2}, i_{1}, i_{2}\right)$ and the households' saving after period 1 is:

$$
\begin{aligned}
W_{1}\left(A_{1}, A_{2}, i_{1}, i_{2}\right)= & i_{1} W_{0}+r_{1} T_{1}\left(A_{1}, A_{2}, i_{1}, i_{2}\right)+w_{1}\left(A_{1}, i_{1}\right) \\
& -C_{1}\left(A_{1}, A_{2}, i_{1}, i_{2}\right)-p_{1} H_{1}\left(A_{1}, A_{2}, i_{1}, i_{2}\right) .
\end{aligned}
$$

The market-clearing conditions in capital markets are:

$$
\begin{aligned}
W_{0} & =K_{1}\left(A_{1}, i_{1}\right)+S_{1}\left(A_{1}, A_{2}, i_{1}, i_{2}\right) & & (\text { for } \mathrm{t}=1), \\
W_{1}\left(A_{1}, A_{2}, i_{1}, i_{2}, W_{0}\right) & =K_{2}\left(A_{2}, i_{2}\right)+S_{2}\left(A_{1}, A_{2}, i_{1}, i_{2}\right) & & (\text { for } \mathrm{t}=2) .
\end{aligned}
$$

With these two equations, in principle two unknowns $\left(i_{1}, i_{2}\right)$ can be solved for in terms of the exogenous variables $A_{1}, A_{2}, W_{0}$. Numerical solutions must be used to obtain the actual solutions. In the case of CES-CRRA, capital markets' equilibria will depend additionally on the housing rents. Therefore, the housing-market equilibrium and the capital-market equilibrium are solved simultaneously. In this paper, basic parameters are set as follows: $\alpha=1 / 3, \beta=0.9, \gamma=0.7$, and $\delta=0.5$. 